\title{
Characterization of S40-like proteins and their roles in response to environmental cues and leaf senescence in rice
}

\author{
Xiangzi Zheng ${ }^{\dagger}$, Muhammad Jehanzeb ${ }^{\dagger}$, Habiba $^{\dagger}$, Yuanyuan Zhang, Li Li and Ying Miao ${ }^{*}$ (D)
}

\begin{abstract}
Background: Senescence affects the quality and yield of plants by regulating different traits of plants. A few members of 540 gene family, the barley HvS40 and the Arabidopsis AtS40-3, have been shown to play a role in leaf senescence in Barley and Arabidopsis. Although we previously reported that $\$ 40$ family exist in most of plants, up to now, no more function of S40 members in plant has been demonstrated. The aim of this study was to provide the senescence related information of $\$ 40$ gene family in rice as rice is a major crop that feeds about half of the human population in the world.

Results: A total of 16 Os\$40 genes were identified from the genome database of Oryza sativa L. japonica by bioinformatics analysis. Phylogenetic analysis reveals that the 16 Os\$40 proteins are classified into five groups, and 4 of the 16 members belong to group I to which also the HvS40 and AtS40-3 is assigned. S40 genes of rice show high structural similarities, as 13 out of the 16 genes have no intron and the other 3 genes have only 1 or 2 introns. The expression patterns of Os $\$ 40$ genes were analyzed during natural as well as stress-induced leaf senescence in correspondence with senescence marker genes. We found that 6 of them displayed differential but clearly upregulated transcript profiles under diverse situations of senescence, including darkness, nitrogen deficiency, hormone treatments as well as pathogen infection. Furthermore, three Os\$40 proteins were identified as nuclear located proteins by transient protoplast transformation assay.
\end{abstract}

Conclusions: Taking all findings together, we concluded that OsS40-1, OsS40-2, OsS40-12 and Os S40-14 genes have potential regulatory function of crosstalk among abiotic, biotic and developmental senescence in rice. Our results provide valuable baseline for functional validation studies of the rice $\$ 40$ genes in rice leaf senescence.

Keywords: S40 protein family, Leaf senescence, Rice, Expression profiling, Environmental cues

\section{Background}

Leaf senescence is an integral part of the final stages of plant development, and is controlled by a fine-tuned complex regulatory network [1]. Internal factors such as age of plants, hormones and external (a) biotic factors affects the regulation of leaf senescence [2]. Thousands of genes shows differential expression pattern at the onset and during the development of senescence [3, 4]. It has revealed a wide range changes in gene-expression during senescence in many plants such as Arabidopsis

\footnotetext{
* Correspondence: ymiao2013@hotmail.com; ymiao@fafu.edu.cn

${ }^{+}$Xiangzi Zheng, Muhammad Jehanzeb and Habiba contributed equally to this work.

Fujian Provincial Key Laboratory of Plant Functional Biology, College of Life Sciences, Fujian Agriculture \& Forestry University, Fuzhou, China
}

$[4,5]$, wheat [6], barley [7], rice [8] and aspen [9]. Senescence is a highly organized process that requires specific genes expression $[10,11]$ referred as senescence associated genes (SAGs) that account for $10 \%$ of a plant genome $[3,12]$. Most of the SAGs are not only expressed during age dependent senescence, but are also expressed during stress induced senescence, such as wounding, darkness, desiccation, treatments of the leaves with hormones and in response to pathogen infections $[2,13]$. These SAGs are activated by different transcription factors (TFs), among which NAC and WRKY are the two major groups that are involved in plant senescence [3]. Hence the expression of numerous SAGs can be influenced by the regulation of a specific gene that encodes a specific TF [14]. 
Despite the fact that senescence strongly influence yield of crop plants, only few SAGs had been isolated from crop plants such as wheat and barley [15], before the employment of microarrays for studies on wheat and barley leaf senescence [16, 17]. In barley, $H v S 40$ is shown to be senescence marker gene $[18,19]$. The $H \nu S 40$ gene is up-regulated during natural senescence of barley primary leaves as well as dark induced senescence of detached leaves [18-21]. In a transcriptome study, the orthologous gene of wheat also showed enhanced expression during senescence of flag leaves [16]. Similarly in Arabidopsis, Seven of eleven genes, AtS40-1, AtS402, AtS40-3, AtS40-4, AtS40-5, AtS40-6 and AtS40-7 showed enhanced transcripts levels in senescent leaves compared to nonsenescent leaves [22]. The expression level of AtS40-1, AtS40-2 and AtS40-5 genes were induced after 2 days of darkness incubation while AtS40-3 and $A t-S 40-4$ showed increased expression only one day after darkness incubation [22]. Furthermore, $\mathrm{HvS4O}$ shows enhanced expression in leaves treated with methyl jasmonate (MeJA), salicylic acid (SA) and infected by Pyrenophora teres [19]. Similarly, the expression levels of three genes AtS40-2, AtS40-3 and AtS40-4 were shown to be significantly increased after treatment of Arabidopsis plants with SA, abscisic acid (ABA) or pathogen Pseudomonas syringae $p v$ for only 1 day [22]. Because of the nuclear localization of HvS40 protein, it is considered a candidate for regulating senescence related genes in the nucleus [19]. After transformation with onion epidermal cells, both the AtS40-3-GUS construct [22] and HvS40-GUS fusion construct showed similar GUS activity distribution in the nucleus [19].

The Arabidopsis T-DNA insertion mutant s40-3a showed delayed senescence compared to the wildtype [22]. The expression levels of WRKY53 and SAG12, marker of early and late changes in gene expression during leaf senescence respectively, were clearly decreased in the $s 40-3 a$ mutant compared to that in wildtype at all stages of senescence [22]. The overall expression analyses of AtS40-3 gene in both the wildtype and mutants proposed that $A t S 40-3$ gene acts as an activator of downstream WRKY53 and SAG12. Similarly, lower expression levels of two SAG markers, SAG12 and SEN1 [23], during dark condition in $s 40-3 a$ mutant in comparison to that in wild type indicated that AtS40-3 positively regulated senescence in both natural light as well as dark conditions [22]. Although we previously reported that S40 family exist in most of plants [24], up to now, no more information of S40 members in rice has been demonstrated.

In this study, we identified rice $S 40$ gene family consisting of 16 genes and analyzed their phylogeny, gene structure, chromosomal location, conserved motif determination, cis- acting elements and physical and chemical parameters prediction. Moreover, we comprehensively analyzed gene expression patterns of OsS40 genes during natural as well as artificially (a) biotics stress induced senescence in correspondence with senescence marker genes using qRT-PCR. The subcellular localization of nine members including two genes showing overlapping expression profile among abiotic, biotic and developmental senescence are also identified. These findings can be used for further functional validation studies of the rice $S 40$ genes in rice leaf senescence.

\section{Results}

Identification and characterization of the rice $\mathbf{S 4 0}$ genes

S40 belongs to DUF584 Family, it contains DUF584 domain, the sequence: GRXLKGR(D/E)(L/M)XXXR(D/

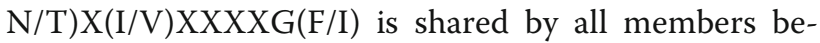
long to DUF584 group. The barley $H v S 40$ gene encodes a member of the DUF584 group gene while in Arabidopsis, fifteen proteins belong to this family that was classified into five groups based on similarities of their amino acid sequences [22]. To identify S4O like genes in rice, HvS40 protein sequence was blasted as a query sequence against the rice genome. In total, sixteen similar hits were found in rice genome and these genes were tentatively named OsS40-1 to OsS40-16 (Table 1). The complete open reading frames (ORFs) of the retrieved OsS4O genes ranged from $393 \mathrm{bp}$ (OsS40-2 and OsS40-7) to $780 \mathrm{bp}$ (OsS40-10) (Table 1).

To characterize the structural diversity of the OsS40 genes, exon/intron organization analysis of the individual OsS40 genes was performed. Number of exons and introns of $S 40$ genes in rice were calculated using Gene Structure Display Server database (http://gsds.cbi.pku. edu.cn/). S40 genes of rice showed high structural similarity, as 13 out of the 16 genes have no introns while the other 3 genes have only 1 or 2 introns. Moreover, 5 genes, including OsS40-2, OsS40-3, OsS40-8, OsS40-12 and OsS40-16, have no untranslated regions (UTR) (Additional file 1: Figure S1).

To gain insight into the organization of $S 40$ genes in rice, the chromosomal location of the OsS40 genes was analyzed. Chromosome Map Tool from integrated rice science database (http://viewer.shigen.info/oryzavw/map tool/MapTool.do) was used to locate OsS40 genes on chromosome. It revealed that 9 out of 16 OsS40 genes are distributed among three chromosomes (Chr1, Chr4 and Chr5), while none of the genes are located on four chromosomes (Chr2, Chr6, Chr8 and Chr9). The other chromosomes contain one or two $S 40$ genes (Additional file 2: Figure S2). High-density OsS40 gene clusters were mapped in certain chromosomal regions, e.g., in the proximal regions of Chr1 and Chr7 and in the distal regions of $\mathrm{Chr} 4$ and $\mathrm{Chr} 5$ (Additional file 2: Figure S2). 
Table 1 Overview of $\$ 40$ genes identified in rice genome and their predicted expression patterns in different tissues (http://bar. utoronto.ca/efprice/cgi-bin/efpWeb.cgi)

\begin{tabular}{|c|c|c|c|c|c|c|c|c|c|c|c|}
\hline \multirow[b]{2}{*}{ Gene name } & \multirow[b]{2}{*}{ Gene Locus } & \multirow[b]{2}{*}{ Chromosome } & \multirow[b]{2}{*}{ ORF (bp) } & \multirow[b]{2}{*}{ No. of exons } & \multicolumn{7}{|c|}{ Expression profiles in rice tissues } \\
\hline & & & & & Seed & $\begin{array}{l}\text { Young } \\
\text { leaf }\end{array}$ & $\begin{array}{c}\text { Mature } \\
\text { leaf }\end{array}$ & SAM & $\begin{array}{l}\text { Seedling } \\
\text { root }\end{array}$ & $\begin{array}{c}\text { Young } \\
\text { Inflorescence }\end{array}$ & $\begin{array}{c}\text { Mature } \\
\text { inflorescence }\end{array}$ \\
\hline Os $S 40-1$ & LOC_Os05g45450 & 5 & 429 & 1 & High & Low & Low & No & High & No & Low \\
\hline$O s S 40-2$ & LOC_Os05g44260 & 5 & 393 & 1 & - & - & - & - & - & - & - \\
\hline OsS40-3 & LOC_Os10g27350 & 10 & 759 & 1 & Low & Low & Low & Low & Low & Low & Low \\
\hline OsS40-4 & LOC_Os03g02280 & 3 & 594 & 1 & High & Low & High & High & High & High & High \\
\hline Os $S 40-5$ & LOC_Os04g45834 & 4 & 630 & 1 & Low & No & Low & Low & No & No & No \\
\hline Os $S 40-6$ & LOC_Os04g33760 & 4 & 738 & 1 & High & Low & High & High & High & High & High \\
\hline OsS40-7 & LOC_Os01g52730 & 1 & 393 & 1 & High & High & High & Low & High & High & High \\
\hline Os $S 40-8$ & LOC_Os10g33990 & 10 & 534 & 2 & - & - & - & - & - & - & - \\
\hline Os $S 40-9$ & LOC_Os01g64300 & 1 & 660 & 1 & High & High & High & High & High & High & High \\
\hline OsS40-10 & LOC_Os01g52740 & 1 & 780 & 3 & - & - & - & - & - & - & - \\
\hline OsS40-11 & LOC_Os12g05980 & 12 & 498 & 1 & - & - & - & - & - & - & - \\
\hline Os $S 40-12$ & LOC_Os11g05600 & 11 & 516 & 1 & - & - & - & - & - & - & - \\
\hline Os $S 40-13$ & LOC_Os04g43990 & 4 & 525 & 1 & High & Low & High & High & High & High & High \\
\hline Os $540-14$ & LOC_Os05g45440 & 5 & 450 & 1 & High & High & High & No & Low & High & High \\
\hline OsS40-15 & LOC_Os07g 33270 & 7 & 591 & 1 & High & Low & High & Low & High & High & High \\
\hline OsS40-16 & LOC_Os07g32810 & 7 & 477 & 1 & No & Low & No & No & Low & No & No \\
\hline
\end{tabular}

ORF open reading frame, No. number, SAM shoot apical meristem

These data may provide helpful information concerning the expansion of the rice $S 40$ gene family.

\section{Phylogenetic relationships of the rice $\mathbf{S} 40$ genes}

To survey the possible evolutionary relationships between 540 proteins from rice and previously reported S40 proteins from Arabidopsis and barley [22, 24], sequence alignments were performed and an un-rooted phylogenetic tress of 16 OsS40s, 15 AtS40s and 5 HvS40s was constructed using neighbor joining (NJ) method by MEGA 6.0 with 1000 bootstrap replicates. It indicated that the S40 family proteins of rice, Arabidopsis and barley could be classified into 5 groups (Fig. 1). 4 of the 16 DUF584 proteins of rice belong to group I to which also the HvS40 and AtS40 is assigned. From the further proteins of rice, 2 are present in group II and III each while only one protein appears in group IV. By contrast, $7 \mathrm{~S} 40$ proteins of rice cluster in group V, which contains only one Arabidopsis protein and two barley proteins (Fig. 1). No apparent similarity was identified by comparing amino acid sequences of the two S40 proteins of rice, four of Arabidopsis and one of barley from group I to the amino acid sequence of HvS40 protein. However, all the compared protein sequences shared the conserved DUF584 domain sequence (Additional file 2: Figure S3).

The phylogenetic relationship and classification of S40 members in rice were further supported by motifs analysis. Ten individual motifs, designated motif 1 to 10 , for 16 rice S40 proteins, AtS40-3 and $\mathrm{HvS40}$ were sensitized using MEME software (Additional file 2: Figure S4). As predicted, DUF584 domain corresponded to motif 1 , whereas the functions of the other putative motifs were elusive since they lacked homologs in protein motif database SMART or Pfam. Motifs 1, 2, 3 and 4 were present in all these proteins while other motifs have specific distributions among different proteins. Motif 8 or motif 9 was clade-specifically distributed in protein members that belong to group I. Furthermore, OsS40-2 and HvS40 showed similar motif distribution patterns. AtS40-3 is unique in motif distribution patterns because of the presence of motif 9 and the most similar rice S40 proteins to AtS40-3 are OsS40-16 and OsS40-14 (Additional file 2: Figure S4), implying functional similarities among these $\mathrm{S} 40$ members.

\section{Cis elements comparison in the promoters of HvS40, AtS40-3 and 0 s 540 genes}

To uncover cis elements that might be involved in the initiation of $S 40$ gene transcription during senescence and to explore elements related to developmental senescence, the promoter of the $S 40$ genes in rice was revealed using PlantCARE database (http://bioinformat ics.psb.ugent.be/webtools/plantcare/html/) and compared with the promoters of AtS40-3 and HvS4O [25]. Except OsS40-11, the upstream of OsS40 genes as well as $\mathrm{HvS40}$ and $\mathrm{AtS40-3}$ genes showed the presence of W-Boxes $(\mathrm{C} / \mathrm{T}) \mathrm{TGAC}(\mathrm{T} / \mathrm{C})$, the elements known to be the binding site of WRKY TFs [26]. In addition, many MYC (MYC TF recognition sites [27]), MYB (MYB TF 


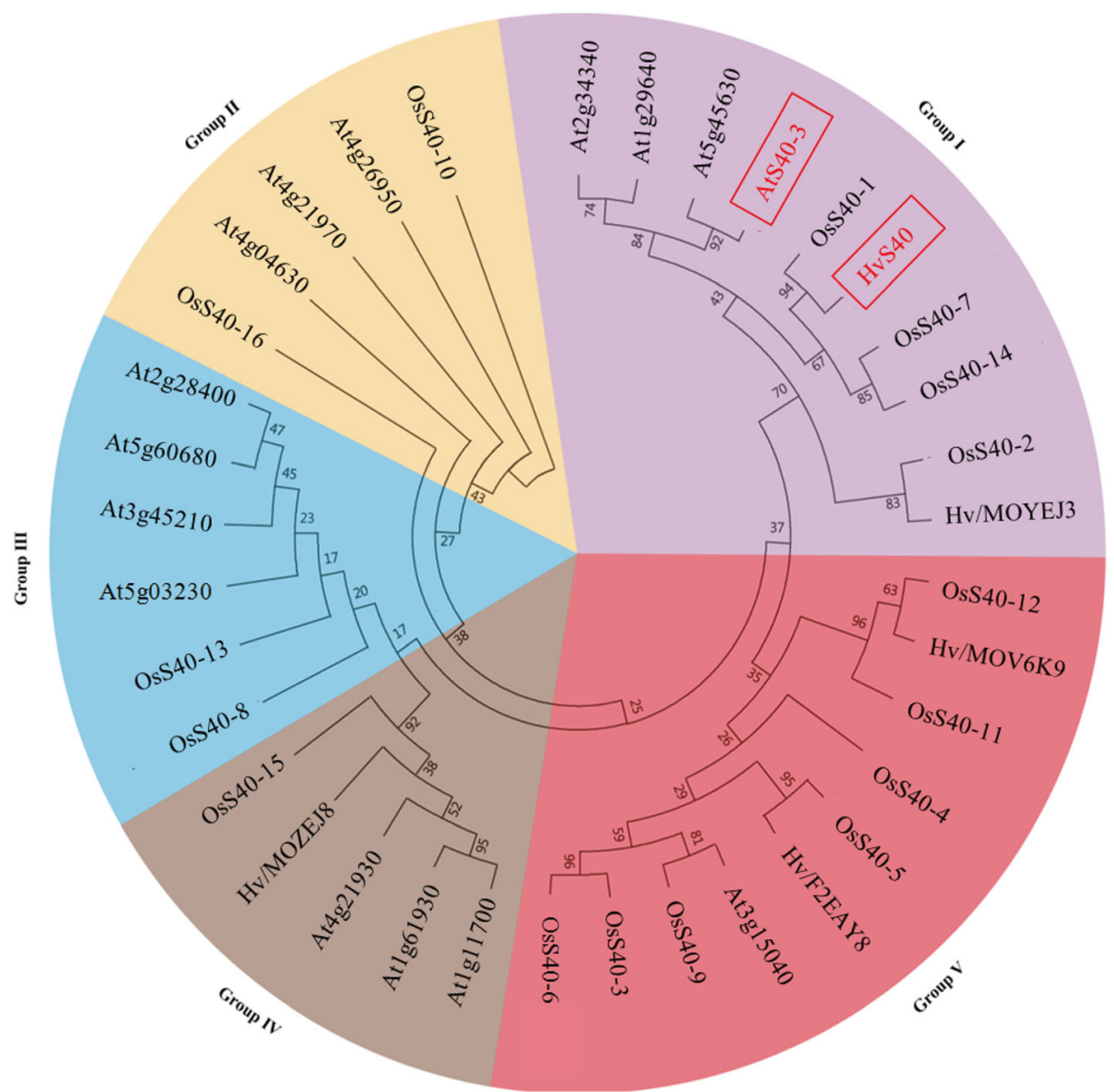

Fig. 1 Phylogenetic analysis of the DUF584-family proteins from Arabidopsis, barley and rice. The un-rooted phylogenetic tree was constructed using MEGA 6.0 and the Neighbor-Joining method. The full length amino acid sequences were aligned using ClustalW. The bootstrap test was performed with 100 iterations. AT (Arabidopsis), Os (Rice) and Hv (Barley)

recognition sites [27]) and Dof (Dof proteins core binding sites [28] were found in the promoters of all rice $S 40$ genes as well as $\mathrm{HvS4O}$ and $\mathrm{AtS40-3}$ (Additional file 2: Table S1), suggesting that the promoters of S40 genes might be targeted by different TFs. Abundant CGCG boxes (Motifs recognized by calmodulin-binding proteins, which involved in multiples signaling pathways in plants [29]) and several ABA-responsive elements (ABRE) recognition sequences [30] were identified in promoter regions of some rice $S 40$ genes while no CGCG box region was found in AtS40-3 gene promoter. Moreover, a few dehydration-responsive elements/C-repeats (DRE/CRT) [31] and low-temperature responsive elements (LTRE) [32] were synchronously present in the promoters of $8 \mathrm{OsS40}$ genes as well as $\mathrm{H \nu S4O}$ while only one LTRE appeared in AtS40-3 promoter (Additional file 2: Table S1). This information implied that transcripts of rice $S 40$ genes might be affected by different environmental and developmental conditions, as has been shown in the study of $H v S 40$ [19, 33, 34]. In potato, a single-strand DNA binding factor, StWHIRLY1, was shown to bind to the elicitor response elements (ELRE) identified in the promoter of PR10a $[35,36]$. Recently, it has been demonstrated that two ELRE elements in the promoter region of $H \nu S 40$ gene can interact with HvWHIRLY1 [33]. However, ELRE elements were rarely observed in promoter sequences of OsS40 genes as only one ELRE was found in the promoters of OsS40-7, OsS40-13, OsS40-15 and OsS40-16 (Additional file 2: Table S1).

\section{Expression profiles of $0 s 540$ candidate genes during natural senescence}

Generally, plants grown under ideal conditions will undergo natural senescence, which is primarily controlled developmentally. To obtain clues regarding possible functions of OsS40 genes in different tissues during plant development of rice, an overview of expression changes of these OsS4O candidates in seed, root, shoot apical meristem (SAM), developing leaves as well as inflorescence was obtained from the rice eFP Browser (http://bar.utoronto.ca/efprice/cgi-bin/efpWeb.cgi) [37]. 
Although transcript data of some OsS40 members is not available from the database, the remaining rice $S 40$ genes displayed differential expression patterns in these organs (Table 1). OsS40-9 looked highly expressed throughout rice development. On the contrary, OsS403, OsS40-5 and OsS40-16 transcripts were low or undetectable in all these tissues examined. It was noted that the transcript value of OsS40-4, OsS40-6, OsS4013 and OsS4-15 was low in young leaf, but high in mature leaf (Table 1), implying their involvement in natural development of rice leaf.

Rice flag leaf is proposed to serve as a determinant for grain yield, since flag leaves not only supply the seeds carbon components by photosynthesis but also transport the useful nutrients from senescent leaves into young panicles during the grain-filling period [38, 39]. Characterization of OsS40 genes during natural senescence of flag leaves would be more valuable for understanding the mechanisms of flag leaf senescence and favoring grain yield. For collecting the senescent flag leaves, rice plants were grown to the ripening stage (4 months). The plants were keenly observed for their phenotypic changes, as yellowing color is one of the striking signals of senescence. The yellowish phenotype was observed at 90th day after germination (DAG) and on the same day, samples were collected as the onset of senescence. Furthermore, samples were collected for four times with some interval, at the onset of senescence: 90DAG, 97DAG, 104DAG, 111DAG, 118DAG (Fig. 2 a, b). To determine transcript profiles of rice S40 genes at different late development stages of flag leaves, primers were designed for all the sixteen members and used for RT-PCR. Six of the sixteen genes, OsS40-4, OsS40-5, OsS407, OsS40-9, OsS40-14 and OsS40-15 showed differential expression level during semi quantitative RT-PCR analysis (Additional file 2: Figure S5). The results were confirmed by qRT-PCR (Fig. 2c). Among the six altered expressed genes, three belong to group V, two belong to group I and one is the single group IV gene. The gene expression tendency showed increased
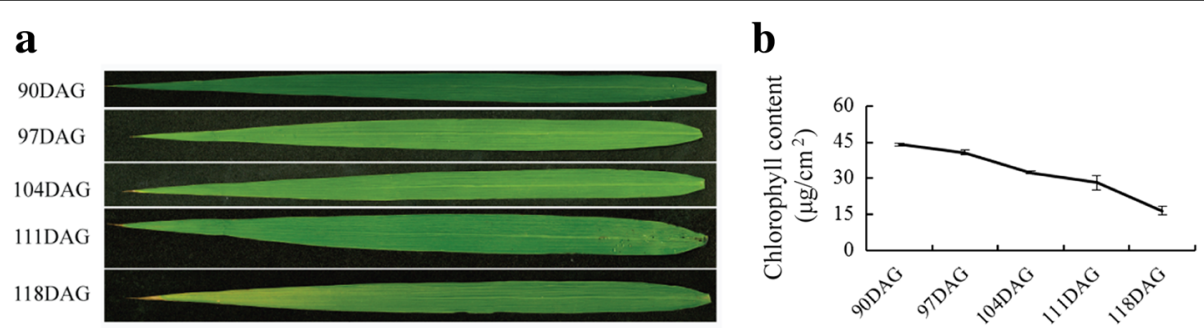

C
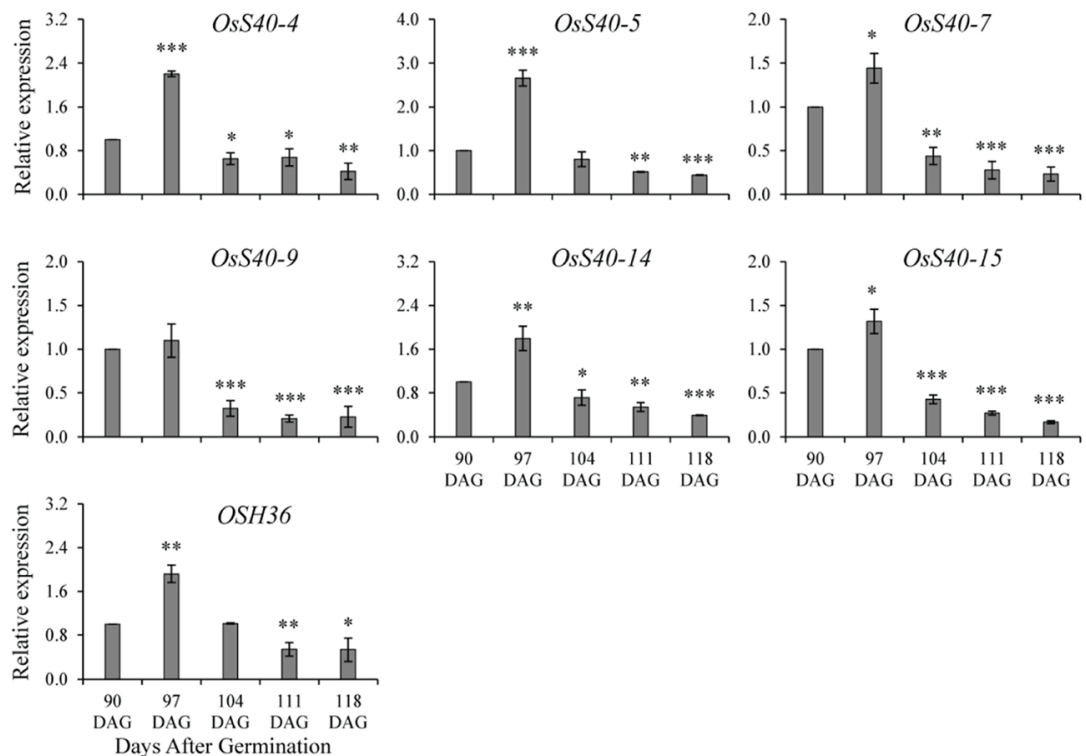

Fig. 2 Expression analysis of Os 540 genes during natural senescence of flag leaves. a Phenotype of rice flag leaves collected at different late development stages (90DAG, 97DAG, 104DAG, 111DAG, 118DAG). DAG, Days after germination. b Development dependent alteration of chlorophyll content in rice flag leaves. c qRT-PCR analyses of the six differentially expressed Os 540 genes along with senescence marker gene, OSH36. Transcript levels are expressed relative to that of rice actin in each sample, and values are mean \pm S.D. Student t-test was used to generate $P$ value. ${ }^{*} P \leq 0.05,{ }^{*} P \leq 0.01$ and ${ }^{* *} P \leq 0.001$ 
expression level at early senescence to decreased expression level at late senescent leaves. One of the senescence associated genes, OSH36 [40], also showed the same expression pattern as a positive control. Overall, our results demonstrated that these six members of the OsS40 family showed enhanced expression at the onset of senescence while showed a decreased expression pattern at later stage of senescence.

\section{Expression profiles of OsS40 candidate genes during nitrogen stress}

Nutrient deficiency, in particular the limitation of nitrogen $(\mathrm{N})$, has been proved to be capable to accelerate plant senescence. Early leaf senescence under low-N supply and delayed leaf senescence upon surplus-N supply has been demonstrated by several reports [41-43]. Precocious flag leaf senescence caused by nitrogen starvation can result in yield decrease [44]. Thus we examined the expression levels of these OsS4O genes in senescent flag leaves of rice growing under low- $\mathrm{N}$ or surplus- $\mathrm{N}$ conditions. To test the effect of altered $\mathrm{N}$ availability on rice development, an experimental condition was designed in which hydroponic culture system was used with only roots submerged in growth medium. Rice plants were separately cultured in three different types of growth media containing normal nitrogen supply (Normal-N) used as a control, half of the normal nitrogen supply (Low-N) or double of the normal nitrogen supply (High-N) compared to control. Rice plants grown in the medium with deficient $\mathrm{N}$ availability showed earlier senescence, while plants with excessive supply of $\mathrm{N}$ showed delayed senescence compared to the control plants (Fig. 3a). The relative photochemical efficiency of photosystem II $(\mathrm{Fv} / \mathrm{Fm})$ of entire rosettes was similar in all types of plants while the chlorophyll content were decreased in lower nitrogen supplied plants compared to normal nitrogen supplied plants (Fig. 3b, c).

To identify OsS4O genes with common and distinct expression patterns in response to altered $\mathrm{N}$ supply, flag leaves were collected at 90DAG from rice plants growing in all the three types of media and gene expressions were analyzed via semi qRT-PCR at first. Nine out of the sixteen OsS40 genes showed detectable expression in the control sample (Normal-N) and 6 among them, OsS401, OsS40-2, OsS40-4, OsS40-6, OsS40-10 and OsS4012 , displayed differential expression upon changed $\mathrm{N}$ supply (Additional file 2: Figure S6). These 6 differentially expressed genes were further analyzed by qRT-PCR that confirmed the enhanced transcript levels of these six genes. However, the expressions of all these six genes were up-regulated in plants supplied with low $\mathrm{N}$ compared to control (Normal-N), while their expression patterns were similar between control and high $\mathrm{N}$ supply (Fig. 3c), suggesting these six OsS40 members may take part in the early senescence of flag leaves caused by $\mathrm{N}$ limitation, but not participate in the delayed senescence induced by surplus $\mathrm{N}$ supply. Two of the six up-regulated genes, OsS40-1 and OsS40-2, belong to group I to which $\mathrm{HvS4O}$ in Barley [19] and AtS4O-3 in Arabidopsis [22] also belong. OSH36 [40], as a positive control, also showed the similar expression pattern .

\section{Expression profiles of OsS40 candidate genes in response to darkness treatment}

Chlorophyll degradation and protein catabolism are some typical symptoms of senescence process. Dark-induced senescence has frequently been used as a model system to promote these symptoms to study natural senescence in plants $[13,45]$. The barley $H \nu S 40$ was first identified as a SAG due to its elevated mRNA level during darkness-induced senescence of detached leaves [18]. To explore which of the OsS40 members belong to dark-induced SAGs, these candidate genes were tested for expression after darkness treatment. When the detached rice leaves floating on water were incubated in darkness for 2 days, a visible yellowing phenotype was observed on the treated leaves but not on the control leaves (Fig. 4a), indicating that the accelerated senescence process occurred after dark incubation. Via semi qRT-PCR, four of the sixteen genes, OsS40-1, OsS40-2, OsS40-12 and OsS40-14, showed upegulated expression levels in the leaves exposed to darkness for 2 days (Additional file 2: Figure S7). Analysis by qRT-PCR further confirmed the enhanced transcript levels of these four genes as well as the dramatic induction of several senescence marker genes, including OsNAP, OSH36 and Os157, in the dark-treated leaves (Fig. 4b). This result indicated that the four OsS40 members are possibly implicated in dark-induced leaf senescence.

\section{Expression profiles of OsS40 candidate genes in response to hormones}

Phytohormones like JA, SA, ABA, and ethylene has been described as inducers of leaf senescence, while gibberellic acid, cytokinins and auxin result in delayed leaf senescence $[46,47]$. To test the influence of hormones on rice leaf senescence, mature leaves from 4 weeks old plants were harvested by cutting at the approximate middle of the petioles with a sharp scalpel to minimize wounding effects. The detached leaves were then floated in different concentrations $(50 \mu \mathrm{M}$, $100 \mu \mathrm{M}, 200 \mu \mathrm{M})$ of ABA, SA, MeJA or IAA for 0 , 24, 48 and $72 \mathrm{~h}$ (hrs) to examine the effect of different doses of hormones and the time points were noted. Compared to water treatment, a clear promotion of yellowing was observed on leaves when incubated for $48 \mathrm{~h}$ floating on the four $200 \mu \mathrm{M}$ hormone solutions (Fig. 5a and Additional file 2: Figure S8), 


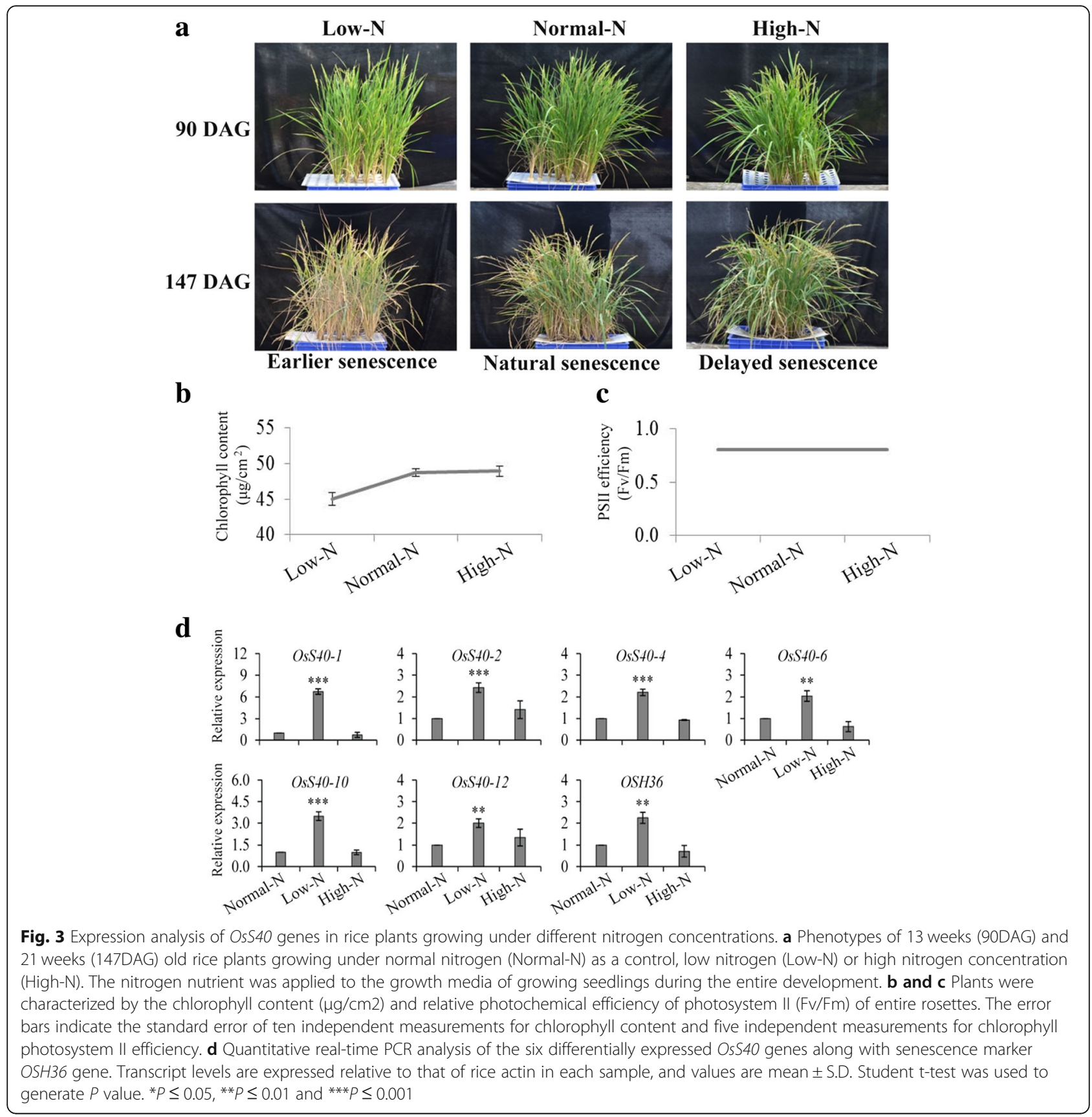

suggesting that leaf senescence was significantly accelerated upon these hormone treatments. To identify the effect of different hormones on expression patterns of OsS40 genes, samples were collected after $24 \mathrm{~h}, 48 \mathrm{~h}$ and $72 \mathrm{~h}$ of $200 \mu \mathrm{M}$ concentration of hormones treatment and gene expressions were analyzed via semi qRT-PCR at first. Except OsSO-16, all the OsS40 members showed detectable expression in this experiment and eight among them presented altered transcript levels after treatment with different hormones (Additional file 2: Figure S9), which was further determined by qRT-PCR analysis.
Nearly half of the 16 members, OsS40-1, OsS40-2, OsS40-4, OsS40-5, OsS40-6, OsS40-12 and OsS40-14, displayed enhanced expression patterns in the detached leaves treated with ABA for $48 \mathrm{~h}$ or $72 \mathrm{~h}$, while OsS4013 was only highest expressed at $24 \mathrm{~h}$ after ABA treatment, which may be the early onset of ABA-triggered leaf yellowing (Fig. 5b). After SA treatment, mRNA levels of Os40-4, OsS40-5, OsS40-12 and OsS40-14 were moderately elevated at $48 \mathrm{~h}$ or $72 \mathrm{~h}$, whereas OsS40-6 was highly induced at $24 \mathrm{~h}$, maybe the onset of SA-elicited leaf senescence (Fig. 5b). It is noteworthy 

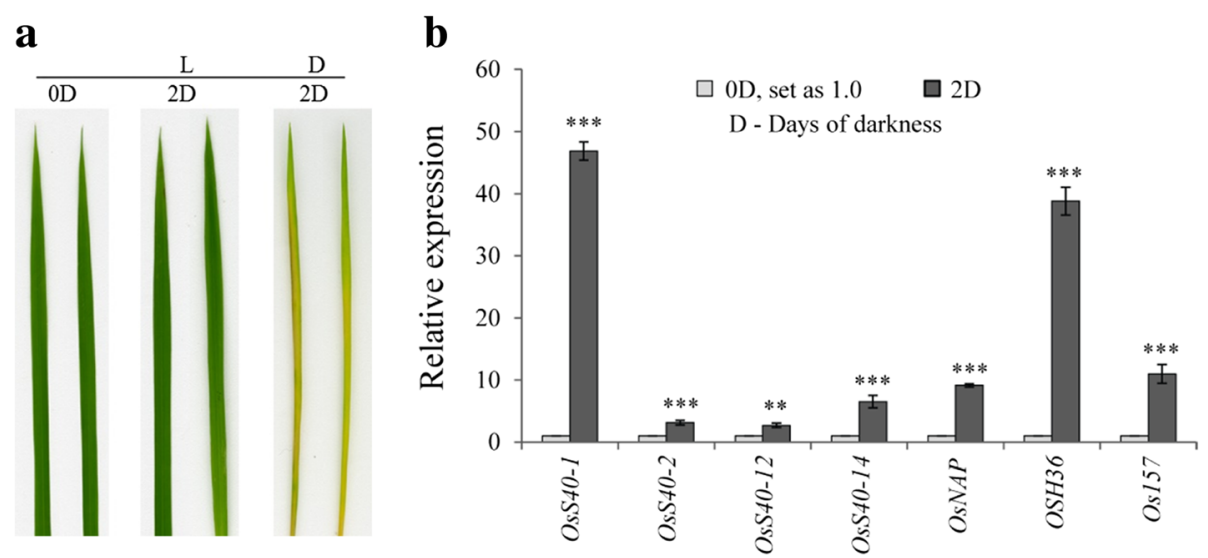

Fig. 4 Expression analysis of Os 540 genes in response to dark treatment. a Phenotype of detached rice leaves after darkness treatment. Detached leaves from 4-week-old rice seedlings were incubated in the deionized water in darkness for 2 days (D). As a control, the detached leaves were incubated with water at the same time in a light/dark regime (L). $\mathbf{b}$ qRT-PCR analysis of the four differentially expressed Os 540 genes along with senescence marker genes, OsNAP, OSH36 and Os157, after darkness treatment. Transcript levels are expressed relative to that of rice actin in each sample, and values are mean \pm S.D. Student t-test was used to generate $P$ value. ${ }^{*} P \leq 0.05,{ }^{* *} P \leq 0.01$ and ${ }^{* * *} P \leq 0.001$

that the seven OsS40 genes strongly responsive to ABA treatment were also markedly up-regulated after exposure to MeJA (Fig. 5b), suggesting that these seven members may play redundant function in the common molecular mechanisms shared by ABA- and MeJA-mediated leaf senescence. As a control, the expressions of several SAG markers, such as OsNAP [48], SGR [49], NYC1 [50], NYC3 [51] and Os157 [40] were also extremely induced upon ABA, SA or MeJA treatments (Fig. 5b). In contrast, only a few genes, OsS40-2, OsS40-5 and OsS40-14, showed accumulated expression levels in respond to IAA, implying that most of OsS40 genes may be not important for IAA-induced leaf senescence. IAA is a biologically active auxin and several lines of evidence support the negative role of auxin in leaf senescence [52-54]. However, it has also been published that overexpressing an auxin-responsive gene, SAUR36, in Arabidopsis displayed an early leaf senescence phenotype [55] and auxin signaling pathway is required for a senescence-associated receptor kinase (SARK) mediated early leaf senescence [56]. Therefore, auxin may also play a promoting role in leaf senescence. Taken together our results (summarized in Table 2) suggest that some of the OsS40 genes may fulfill key roles in crosstalk among multiple hormone-dependent senescence pathways.

\section{Expression profiles of $\mathrm{Os} S 40$ candidate genes in response to pathogen infection}

Many phytohormones, especially SA and JA, have been demonstrated to contribute to systemic-acquired resistance in plant $[57,58]$. Several members of OsS40 gene family showed enhanced expression level in response to SA or MeJA, suggesting that they may play defense-related function during plant-pathogen interaction. To explore the expression of the $S 40$ candidate genes of rice upon infection with fungal pathogen, 3-4 leaf stage of rice seedlings were inoculated by spraying spores of Magnaporthe oryzae strain Guy11. As a control, the rice seedlings were sprayed with the $0.02 \%(w / v)$ Tween 20 solution only. The infected leaves were collected every $24 \mathrm{~h}$ until disease symptoms were clearly visualized at $108 \mathrm{~h}$ post inoculation (hpi) (Fig. 6a). To control the effect of the pathogen, transcript levels of two defense-related marker genes, NAC4 [59] and WRKY45 [60], were also measured during infection with fungus. As anticipated, they both showed a strong induction in the infected rice leaves.

Semi qRT-PCR analysis revealed that 10 out of the 16 genes displayed altered gene expression after treatment of the plants with the fungal pathogen (Additional file 2: Figure S10), which was further confirmed by qRT-PCR analysis. The five genes, OsS40-1, OsS40-2, OsS40-6, OsS4012 and OsS40-14 that were responsive to SA or MeJA treatment, also had elevated mRNA levels in plants infected with M.oryzae. And they all were exclusively highly expressed at the late stage of the fungus infection on rice, when the infected leaves had developed necrotic lesions (Fig. 6 a and b). HvS4O was also reported to have great mRNA accumulation only at the sites of infection with Pyrenophora teres [19]. It is speculated that these five OsS4O genes and HvS4O might be associated with the rapid senescence and cell death caused by necrosis. Additionally, increased transcript level after the infection also appeared in OsS40-8 and OsS40-13, whose expressions were not affected by all the aforementioned treatments. However, OsS40-4, OsS40-11 and OsS40-15 showed decreased expression levels in the infected rice leaves (Fig. 6b), implying that they may play distinct or negative roles in the senescence triggered by pathogen infection. 


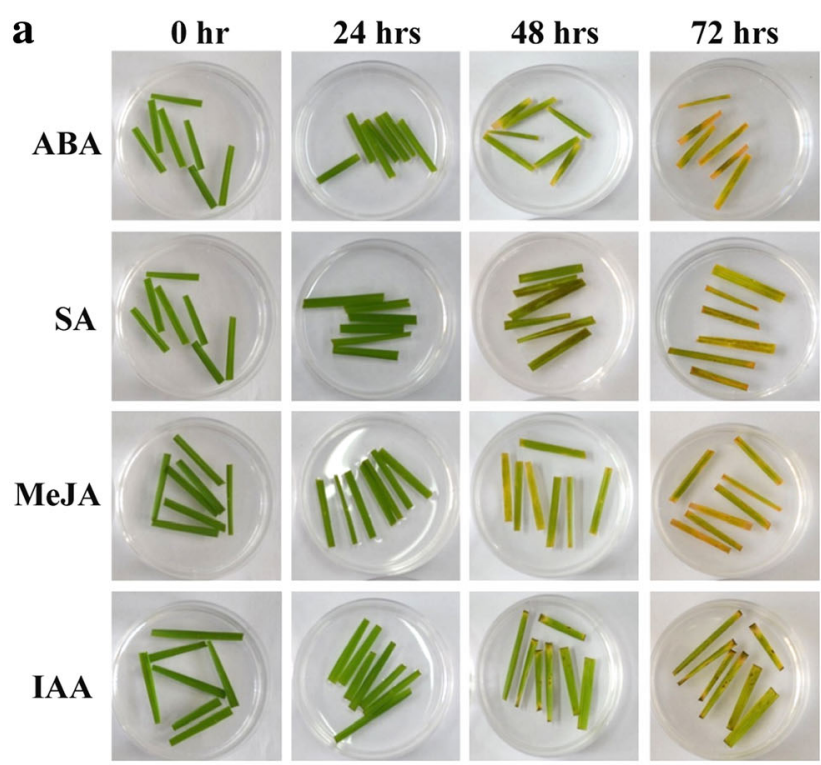

b
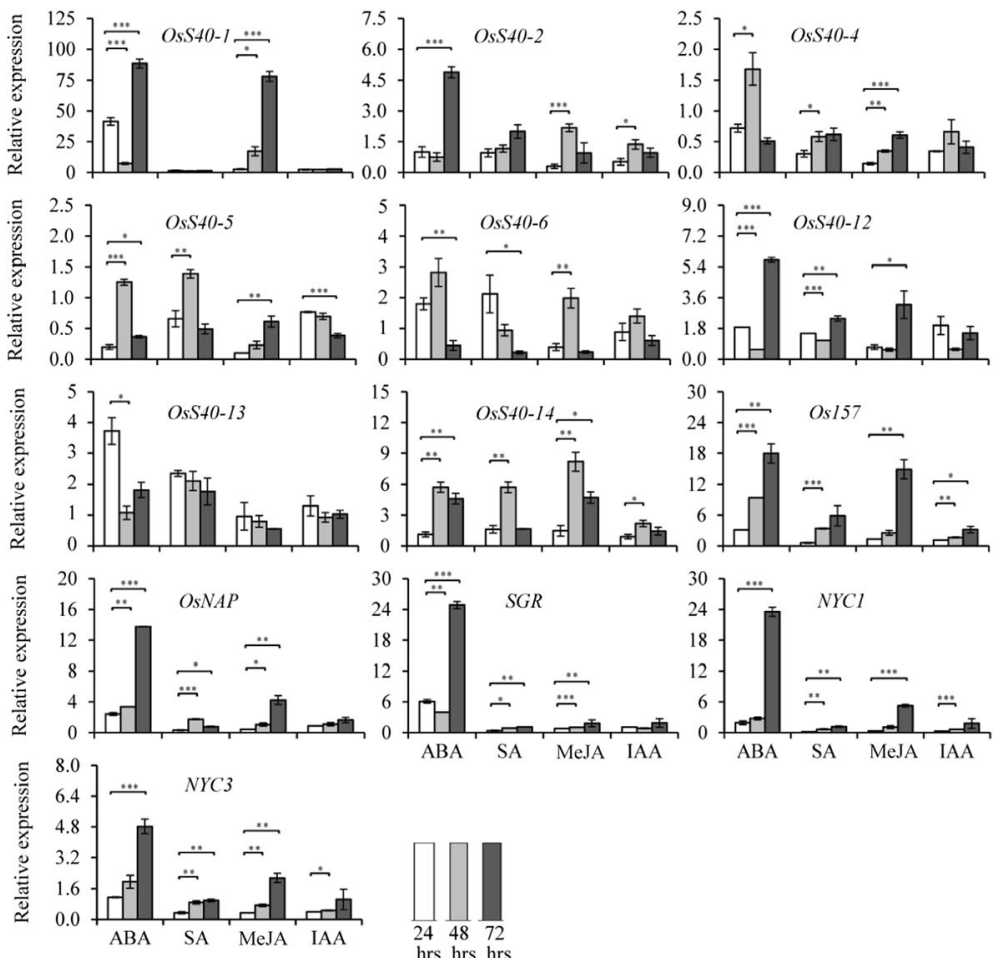

Fig. 5 Expression analysis of Os $\$ 40$ genes under different hormone treatments. a Phenotypes of detached leaves from four weeks old rice plants under different hormone treatments. Photos of detached leaves floating on $200 \mu \mathrm{M}$ concentration of ABA, SA, MeJa or IAA solution were taken at $0 \mathrm{~h}, 24 \mathrm{~h}, 48 \mathrm{~h}$ and $72 \mathrm{~h}$. b Quantitative real-time PCR analyses of the eight differentially expressed Os 540 genes along with senescence marker genes, OSNAP, SGR, NYC1, NYC3 and OS157, upon ABA, SA, MeJA or IAA treatment. Transcript levels are expressed relative to that of rice actin in each sample, and values are mean \pm S.D. Student t-test was used to generate $P$ value. ${ }^{*} P \leq 0.05,{ }^{* *} P \leq 0.01$ and ${ }^{* * *} P \leq 0.001$

\section{Subcellular localization of OsS40 proteins in rice cells} Information's about all these sixteen S40 proteins such as, molecular weight (MW), number of amino acid, theoretical isoionic point (pI), instability index, aliphatic index and GRAVY (Grand Average of Hydropathy) were predicted by Protparam program (http://web.expasy.org/ protparam/) (Additional file 2: Table S2). The value of isoionic point $(\mathrm{pI})$ varied from $5.36(\mathrm{OsS} 40-16)$ to 11.27 
Table 2 Summary of expression profiles of OsS40 genes during natural senescence of flag leaves and in respond to various environmental stresses

\begin{tabular}{|c|c|c|c|c|c|c|c|c|}
\hline \multirow{2}{*}{ Gene names } & \multirow{2}{*}{$\begin{array}{l}\text { Age-dependent flag } \\
\text { leaf senescence }\end{array}$} & \multicolumn{7}{|c|}{ Stress-induced leaf senescence } \\
\hline & & Darkness & Low-N supply & ABA & SA & MeJA & IAA & M. oryzae infection \\
\hline OSS40-1 & Low/no expression & Upregulated & Upregulated & Upregulated & Slight/No change & Upregulated & Slight/No change & Upregulated \\
\hline OsS40-2 & Low/no expression & Upregulated & Upregulated & Upregulated & Slight/No change & Upregulated & Upregulated & Upregulated \\
\hline OsS40-3 & Low/no expression & Low/no expression & Slight/No change & Slight/No change & Slight/No change & Slight/No change & Slight/No change & Slight/No change \\
\hline $0 s 540-4$ & Upregulated & Slight/No change & Upregulated & Upregulated & Upregulated & Upregulated & Slight/No change & Downregulated \\
\hline OsS40-5 & Upregulated & Low/no expression & Low/no expression & Upregulated & Upregulated & Upregulated & Upregulated & Slight/No change \\
\hline OsS40-6 & Slight/No change & Low/no expression & Upregulated & Upregulated & Upregulated & Upregulated & Slight/No change & Upregulated \\
\hline OsS40-7 & Upregulated & Low/no expression & Low/no expression & Slight/No change & Slight/No change & Slight/No change & Slight/No change & Slight/No change \\
\hline$O s S 40-8$ & Low/no expression & Low/no expression & Low/no expression & Slight/No change & Slight/No change & Slight/No change & Slight/No change & Upregulated \\
\hline Os $540-9$ & Upregulated & Slight/No change & Slight/No change & Slight/No change & Slight/No change & Slight/No change & Slight/No change & Slight/No change \\
\hline OsS40-10 & Low/no expression & Low/no expression & Upregulated & Slight/No change & Slight/No change & Slight/No change & Slight/No change & Slight/No change \\
\hline$O s S 40-11$ & Low/no expression & Low/no expression & Low/no expression & Slight/No change & Slight/No change & Slight/No change & Slight/No change & Downregulated \\
\hline OsS40-12 & Slight/No change & Upregulated & Upregulated & Upregulated & Upregulated & Upregulated & Slight/No change & Upregulated \\
\hline Os $540-13$ & Low/no expression & Low/no expression & Low/no expression & Upregulated & Slight/No change & Slight/No change & Slight/No change & Upregulated \\
\hline Os $540-14$ & Upregulated & Upregulated & Low/no expression & Upregulated & Upregulated & Upregulated & Upregulated & Upregulated \\
\hline OsS40-15 & Upregulated & Slight/No change & Slight/No change & Slight/No change & Slight/No change & Slight/No change & Slight/No change & Downregulated \\
\hline OsS40-16 & Low/no expression & Low/no expression & Low/no expression & Low/no expression & Low/no expression & Low/no expression & Low/no expression & Low/no expression \\
\hline
\end{tabular}

(OsS40-11). The corresponding molecular weight varied from $14.14 \mathrm{kDa}(\mathrm{OsS} 40-7)$ to $28.52 \mathrm{KDa}$ (OsS40-10). The molecular weights ranged from with an average of $19.67 \mathrm{kDa}$. Among these proteins, all had an unstable structure except OsS40-13 with the instability index to be 27.77. OsS40-16 was the unstable one with an instability index of 89.11 . All the S40 proteins in rice were found to be hydrophilic proteins with hydrophobicity score (GRAVY) below 0 (Additional file 2: Table S2).

In order to investigate the subcellular localization of OsS40 members in rice cells, their coding regions were fused to the GFP gene and put under the control of the $35 \mathrm{~S}$ CaMV-promoter. Isolated protoplasts from rice seedlings were transformed with these constructs by PEG-mediated transformation. In protoplasts, the expressed OsS40-1-GFP, OsS40-13-GFP and OsS4014-GFP were efficiently accumulated in the nucleus while OsS40-16-GFP was distributed in the cytoplasm. On the other hand, OsS40-3-GFP OsS40-6-GFP OsS40-7-GFP OsS40-9-GFP and OsS40-15-GFP fluorescence were appeared as several speckles in cytoplasm (Fig. 7). Immunodectection experiments confirmed the expression and stability of these OsS40 members in rice cells (Additional file 2: Figure S11).

\section{Discussion}

Several studies have presented that $\$ 40$ genes are related to plant senescence caused by aging or environmental changes, such as barely $\mathrm{HvS40}$ and Arabidopsis AtS40-3 $[19,22,34]$. Genome-wide survey and alignment also showed S40 gene families exist in many plants [24]. In the present study, 16 DUF584-containing members were isolated based on HvS40 protein sequence and further characterized for their expression patterns during senescence as well as their localizations in rice cells. This screening investigation revealed that 6 of the 16 members are in respond to age-dependent or stress-induced leaf senescence. Furthermore, 2 of these candidates, OsS40-1 and OsS40-14, are mainly enriched in nucleus by transient expression in rice protoplast, which is similar to the subcellular distribution patterns of $\mathrm{HvS40}$ and AtS40-3 [19, 22].

In analogy to Arabidopsis S40 family, the 16 OsS40 members are divided into 5 groups and their genes are unevenly interspersed on eight rice chromosomes (Fig. 1, Additional file 2: Figure S2). A unique characteristic of OsS40 genes is that the majority of them have no introns, except OsS40-8 and OsS40-10 with only one or two introns (Additional file 2: Figure S1). It is proposed that genes rapidly regulated during stress contain fewer introns, since many introns may serve as negative feedback time delay loops or directly extend the length of the pre-mRNA, leading to transcription elongation [61-63]. Low intron density has also been observed in Arabidopsis S40 genes and reported in other stress-responsive gene families, such as the late embryogenesis abundant (LEA) gene family [64] and the trehalose-6-phosphate synthase gene family [65]. Although amino acid sequences of the rice S40 proteins do not show high similarity to $\mathrm{HvS40}$ as well as AtS40-3 (Additional file 2: Figure S3), motif composition analysis provides a hint that the function of OsS40-2 may be similar to HvS40, while OsS40-14 and OsS40-16 may be similar to AtS40-3. Albeit DUF584 domain and three conserved motifs can be detected in every OsS40 protein, motif numbers and distribution alter in each of 


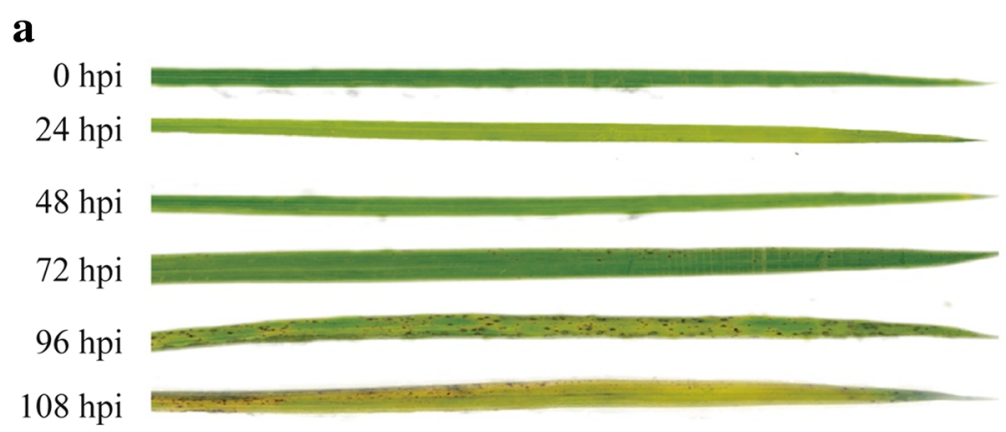

\section{b}
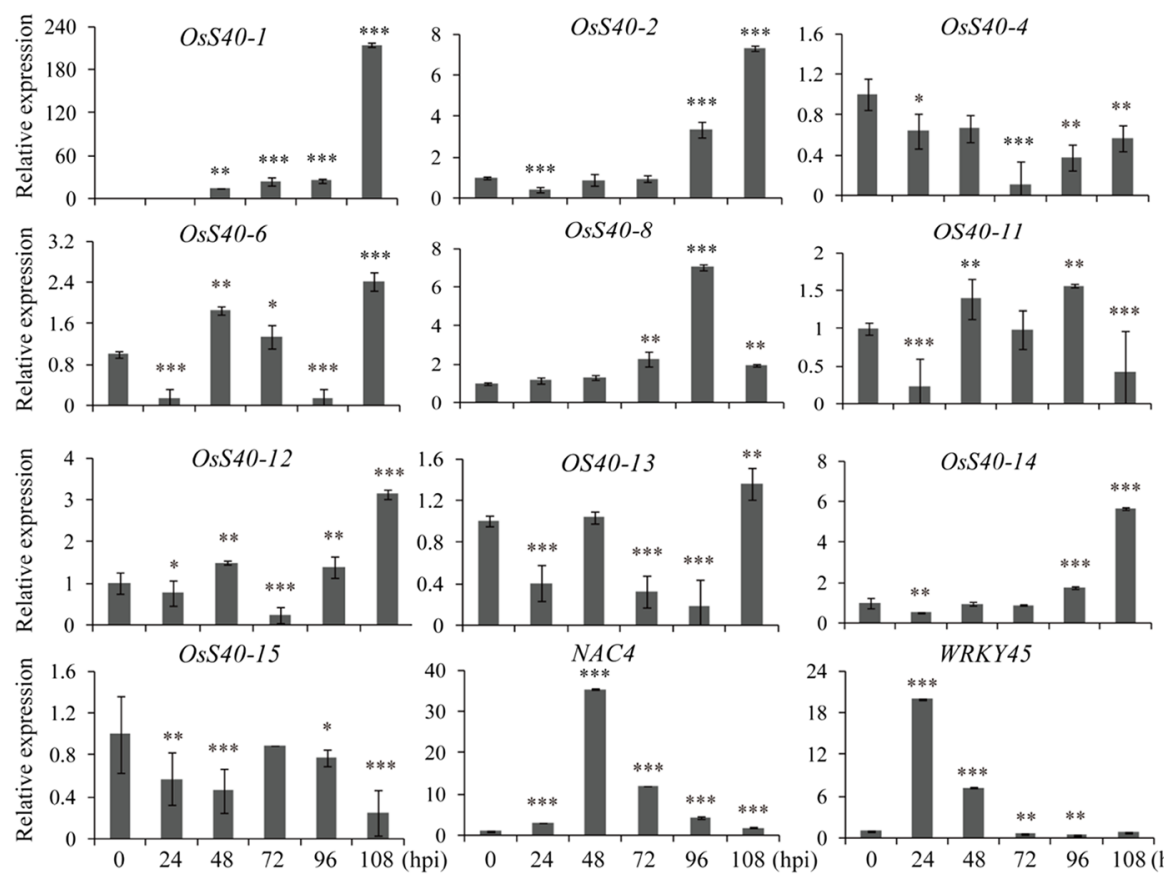

$\underset{* * *}{N A C 4}$
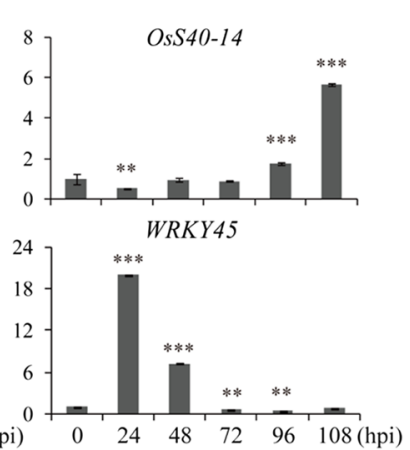

Fig. 6 Expression analysis of Os 540 genes in response to M. oryzae infection. a Phenotype of the leaves from 3 to 4 leaf stage of rice seedlings infected by M. oryzae strain Guy 1. The infected leaves were excised and scanned at 24 hpi, 48 hpi, 72 hpi, 96 hpi and 108hpi. As a control the rice seedlings were sprayed with the $0.02 \%(w / v)$ Tween 20 solution only (Mock). hpi, hours post-inoculation. $\mathbf{b}$ qRT-PCR analysis of the ten differentially expressed Os 540 genes along with the defense-related marker genes, NAC4 and WRKY45, for pathogen treatment. Transcript levels are expressed relative to that of rice actin in each sample, and values are mean \pm S.D. Student t-test was used to generate $P$ value

them (Additional file 2: Figure S4), resulting in disordered structure along their protein sequences, which probably contributes to structural flexibility and thereby enable the proteins to couple with different DNA, RNA or protein targets and carry versatile capability during plant senescence [66]. These results demonstrate that OsS40 genes with few introns encode a series of DUF584 motif-possessing but unstructured proteins, which allow OsS40 proteins to function as flexible interactors to other molecules under stress conditions.

Moreover, plenty of putative TF binding sites, such as W-boxes, MYBs, MYCs and Dofs, as well as stress-responsive elements including ABRE and DRE appear in the promoter regions of rice $S 40$ genes (Additional file 2: Table S1), also implying that they may be regulated by distinct TFs and thus involved in developmental senescence or diverse-stress mediated signaling [67-70]. A DNA binding protein HvWHIRLY1 has been identified as a factor binding to a two-W-box element of the HvS40 promoter in nonsenescent leaves [33]. In Arabidopsis, AtWHIRLY1 has been confirmed as an upstream suppressor of AtWRKY53, which encodes a key positive regulator of leaf senescence [71]. Therefore, HvWHIRLY1 may act as a negative regulator of $H v S 40$ before the onset of senescence [33]. It would be interesting to screen the rice WHIRLY-targeted promoters of OsS40 genes by Chip-qPCR.

In general, the expression pattern of a gene reflects some connection with its function. To investigate the involvement of rice $S 40$ genes in natural senescence of flag 


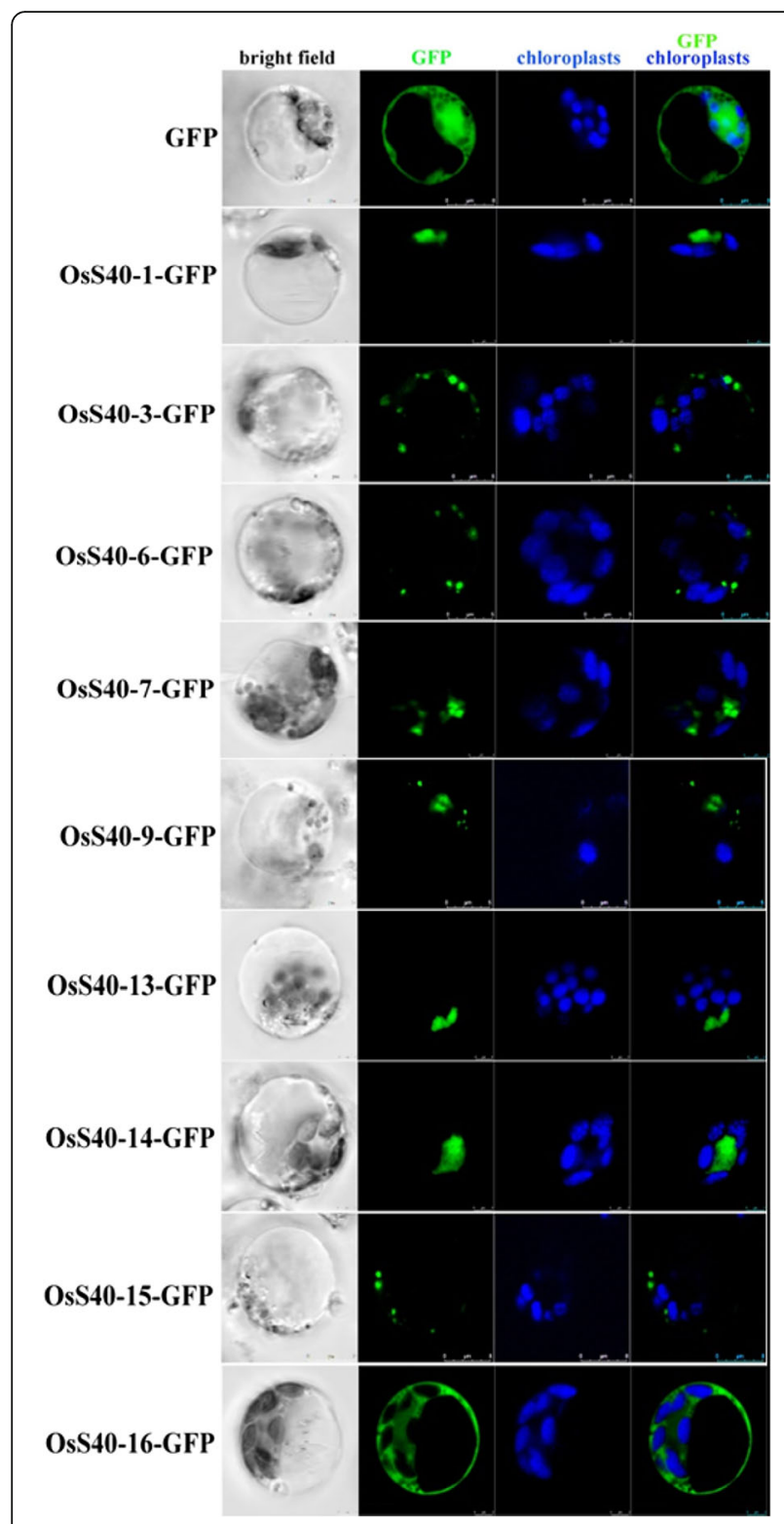

Fig. 7 Subcellular localization of OsS40 proteins. Rice protoplasts transiently expressing Os\$40s-GFP fusion protein were observed using confocal laser scanning microscope after $12 \mathrm{~h}$ transformation. The image shows representative optical sections of bright field and merged fluorescence of GFP (green) and chloroplast (blue) in protoplasts. The right column depicted the merged images

leaf, the expression profiles of OsS40 genes in different stages of flag leaf senescence were examined using semi and quantitative RT-PCR. Six of them showed increased expression at the onset or early stage of flag leaf senescence, but decreased transcript levels at late senescent leaves with less than $20 \%$ of chlorophyll, which is similar to the expression dynamic of OSH36, a confirmed senescence up-regulated gene in rice [40] (Fig. 2). These data indicates that a set of OsS40 genes is probably associated with natural flag leaf senescence in a developmental age-dependent manner. According to the phylogenetic tree, OsS40-1, OsS40-2, OsS40-7 and OsS40-14 together with $\mathrm{HvS40}$ and AtS40-3 belong to the same group (Fig. 1), but OsS40-1 and OsS40-2 were not induced during natural senescence of flag leaf. A simple and likely explanation for this is that low amino acid similarity among their proteins may result in distinct activities of OsS40-1 and OsS40-2 from the other members under the defined experimental conditions. Notably, it is reported that $\mathrm{H \nu S4O}$ and AtS40-3 transcripts accumulated to much higher levels at late senescence stage of barley primary leaves and Arabidopsis rosette leaves, respectively [22,34], while the highest expression level of the six OsS40 genes only appeared at the onset of rice flag leaf senescence. One possibility is that the tissue-dependent gene expression tendency may be inconsistent between senescent flag leaves and mature leaves, given the more important roles of flag leaf during the grain-filling stage $[72,73]$.

Considering that natural senescence is a complex degenerative process causing by the synergy of endogenous aging-development and environmental changes, many SAGs are also high responsive to external stresses inducing leaf senescence [2, 13, 40, 74]. HvS4O looks like a key regulator shared by several senescence-associated pathways owing to the accumulated level of its mRNA under different conditions of senescence [19, 33, 34], while the seven AtS40 genes induced during natural leaf senescence displayed discrete transcript profiles in respond to distinct stress-induced senescence [22]. Previously, we were also aware of the deviation of the predicted expression patterns of OsS40 genes under salt or drought stress [24], assuming that the $\$ 40$ members may play roles in crosstalk among multiple stimuli-promoted senescence pathways. To further confirm this idea, the expressions of all the 16 OsS40 genes were tested under different stress conditions using semi and quantitative RT-PCR. The results (summarized in Table 2) reveal that three OsS40 genes (OsS40-4, OsS40-5 and OsS40-14) involved in the age-dependent flag leaf senescence were also up-regulated upon diverse stimuli treatments ranging from darkness to M.oryzae infection. It is noted that OsS40-14 seems to be a key factor implicated in nearly all the tested stress-mediated senescent processes, except in the nitrogen deficient situation. However, the data of semi RT-PCR reflected that OsS40-14 might be also activated during nitrogen deficiency-induced flag leaf senescence (Additional file 2: Figure S6). Thus the biological function of OsS40-14 in response to environmental stresses deserves further studies.

Similar to AtS40-6 and AtS40-7 [22], the other three age-associated OsS4O genes (OsS40-7, OsS40-9 and OsS40-15) did not show enhanced responses to various stress treatments in our test, with the exception of 
down-regulated OsS40-15 in M.oryzae-infected rice leaves (Table 2), suggesting that they may be specifically related to developmentally controlled senescence pathways. In Arabidopsis, SAG12 is identified as a natural-senescence specific marker, since its transcript level was not significantly affected by stress- or hormone-controlled senescence [13, 75]. It is predicted that the cysteine protease encoded by SAG12 may be deleterious to the cell, resulting in its late expression during senescence [13]. Recently, it has been demonstrated that a repressor in JA-induced leaf senescence, WRKY57, is able to directly bind to the promoter of SAG12 and disturb its transcription [76]. Therefore, we assumed OsS40-7, OsS40-9 and OsS40-15 may function downstream of the convergent senescence-associated pathways.

Additionally, we found that several OsS40 genes, such as OsS40-1, OsS40-2, OsS40-6 and OsS40-12, feature low activity or no influence during flag leaf senescence, but were dramatically induced upon external stresses or hormones treatments (Table 2), which indicates that they may be specific for stress-induced leaf senescence, albeit their transcripts presented limited similarity under distinct stress conditions. It is possible that these stress-dependent OsS40 candidates may function as rapid regulatory components to promote cell death caused by extreme environmental changes. This finding was not mentioned in the study of Arabidopsis S40 family, where only leaf senescence-related AtS40 members were used for further analysis. Therefore, our results extend the knowledge of potential functions of S40 proteins in the senescence-associated complex regulatory network. Gain- and loss-of function experiments may verify the importance of these OsS40 candidates in multiple aspects of rice development and senescence. However, taking account of the possible functional redundancy of these OsS4O genes in different situations of leaf senescence, it should be noted that knockdown or knockout of these OsS40 members may not lead to clear phenotype related to senescence, as has been displayed by deletion studies with Arabidopsis SAG12 [77]. Nevertheless, a recent published computer-based strategy by systematically analyzing the SAG regulating network may contribute to identify key S40 genes modulating leaf senescence [78].

Due to the inclusion of the two putative nuclear localization signals (NLS) in the protein sequence, HvS40-GUS was found to mainly accumulate in the nucleus and partially in the cytoplasm [19]. Rather, most of the reported AtS40 proteins were shown to distribute in the cytoplasm, with the exception of AtS40-3, whose localization resembles that of HvS40 [22]. However, it is worth noting that the investigations on the subcellular targeting of barley HvS40 or Arabidopsis AtS40 proteins were conducted with onion epidermal cells and thus it is possible that the host-specific associations could have impact on the localization pattern in situ. Therefore, the OsS40 proteins, C-terminally fused to GFP, were transiently expressed in rice protoplasts. It revealed that these OsS40 members occupy discrete subcellular compartments in rice cells. OsS40-1, OsS40-13 and OsS40-14 targeted exclusively in the nucleus, while the other members either accumulated as speckles in cytoplasm or distributed in the cytoplasm (Fig. 7), suggesting that they might be regulated by various signals and may execute distinct or redundant functions in rice. In addition, as with $\mathrm{HvS40}$ and AtS40-3, the putative DNA-binding property of OsS40-1 and OsS40-14 has been highlighted by the web-based protein functional families' prediction software SVMProt $[79,80]$. Usually, transcription regulators are localized in the nucleus and coupled with DNA to turn a group of target genes on or off, exemplified by OsNAP [81], OsY37 [82], OsNAC2 [83, 84], which act as positive regulators of leaf senescence. Additional experiments would be necessary to determine the DNA-binding as well as TF activity of OsS40-1 and OsS40-14.

\section{Conclusions}

In this study, a total of $16 S 40$ genes were identified in the genome of rice, which can be classified into 5 groups. Expression profiles of all these OsS40 genes during natural senescence of flag leaf and under various senescence-promoting stress treatments uncovered that a subset of members, including OsS40-1, OsS40-2, OsS40-12 and OsS40-14, were highly stress-responsive. With respect to phylogenetic relationship, transcript data and subcellular distribution, the genes OsS40-1 and OsS40-14 of rice are anticipated to have highest functional similarity to the HvS40 gene of barley or the AtS40-3 gene of Arabidopsis, so their functions merit further investigation. Taking together, this report provides a valuable foundation for subsequent research aimed at understanding the potential roles of S40 family in regulating plant senescence.

\section{Methods}

Identification and phylogenetic analysis of OsS40 proteins To identify $S 40$ like genes in rice (Oryza sativa japonica), HvS40 protein sequence was blasted as a query sequence against the rice genome database (http://plants.ensembl. org/Oryza_sativa/Tools/Blast?db=core). ClustalW was used to perform a multiple sequence alignment of S40 proteins from rice, Arabidopsis and barley. The alignment was then analyzed for phylogenetic tress construction using neighbor joining (NJ) method by MEGA 6.0 with 1000 bootstrap replicates. 


\section{Chromosomal location of OsS40 genes}

To map the locations of $S 40$ like gene transcripts in rice (OsS40), Chromosome Map Tool from integrated rice science database (http://viewer.shigen.info/oryzavw/maptool/Map Tool.do) was employed to visualize the chromosomal distribution. The chromosomal location information of OsS4O genes were obtained from rice database (http://rice.plantbiology.msu.edu/).

\section{Characterization of gene structure and putative cis-acting elements}

The exon-intron structures of OsS40 genes were obtained by mapping the CDS to DNA sequences using the Gene Structure Display Server2.0 (http://gsds.cbi.pku.edu.cn/). CDS and genomic sequences in rice were retrieved from rice database (http://rice.plantbiology.msu.edu/). The 1-kb upstream of the transcription start site $(-1)$ of all identified OsS40 transcripts were extracted as promoter to predict cis-acting elements using PlantCARE database (http://bio informatics.psb.ugent.be/webtools/plantcare/html/).

\section{Conserved motif and chemical characteristics of OsS40 proteins}

To discover motifs in OsS40 protein sequences, the online tool Multiple Expectation Maximization for Motif Elication (MEME) 4.11.2 (http://meme-suite.org/) was utilized to identify the conserved motifs in full-length OsS40 proteins. The optimized parameters were as follows: distribution of motifs, 0 or 1 occurrence per sequence; minimum sites, 6; maximum width 60; maximum number of motifs, 10 .

To give insight into the physical and chemical characteristics of all 16 S40 proteins, 6 indexes including molecular weight, theoretical pI, number of amino acids, instability index, GRAVY and aliphatic index were calculated or predicted by Protparam program (http://web. expasy.org/protparam/).

\section{Plant materials and treatments}

Seeds of rice cultivars, O. sativa subsp. Japonica and Oryza sativa $c v$. CO39, were kindly gifted from Prof. Zonghua Wang (Fujian Agriculture and Forestry University, China). After germination, rice seedlings (O. sativa subsp. japonica) were grown in a growth chamber in the artificial climate chamber with 12 -h-light $\left(28^{\circ} \mathrm{C}\right) /$ 12-h-dark $\left(25^{\circ} \mathrm{C}\right)$ photoperiod. Samples were collected at the initiation of senescence till late senescence at different time points i.e. 90DAG, 97DAG, 104DAG, 111DAG, 118DAG (DAG-Days After Germination).

To analyze nitrogen deficiency induced senescence, rice plants were grown in liquid medium containing normal $\mathrm{N}(1 \mathrm{ml} / \mathrm{L})$, half of the normal $\mathrm{N}(1 / 2 \mathrm{ml} / \mathrm{L})$ and double of the normal $\mathrm{N}(2 \mathrm{ml} / \mathrm{L})$ conc. To analyze hormones induced senescence, detached leaves were floated in 200uM of ABA, SA, MeJA and idole acetic acid (IAA) solution. To analyze dark induced senescence, the plants were placed for 2 days in darkness.

The rice infection assay by $M$. oryzae strain Guy11 was performed. 3 to 4-week-old seedlings of rice (Oryza sativa $c v$. CO39) were inoculated by spraying fungal spores, which were suspended to a concentration of $5 \times$ $10^{4}$ conidia/ml in $0.02 \%(w / v)$ Tween 20 solution. Inoculated plants were kept at $20-23{ }^{\circ} \mathrm{C}$ with $80 \%$ humidity and in the dark for the first $24 \mathrm{~h}$, followed by in a growth chamber at $25^{\circ} \mathrm{C}$ with $80 \%$ humidity for 5 days. For RNA analysis, the infected leaves were excised and pooled at $24 \mathrm{~h}, 48 \mathrm{~h}, 72 \mathrm{~h}, 96 \mathrm{~h}$ and $108 \mathrm{~h}$ after inoculation. As a mock control, the rice seedlings were sprayed with the $0.02 \%(\mathrm{w} / \mathrm{v})$ Tween 20 solution only.

\section{Measurements of chlorophyll content and chlorophyll fluorescence}

Chlorophyll content was measured using the CCM-200 plus Chlorophyll Content Meters instrument. Four leaves of each individual plant were used in the chlorophyll assay. Each leaf was placed at least for 10 points measurement. The average Fv/Fm of all rosette leaves from five individual plants was calculated. Chlorophyll fluorescence measurements were performed using Pocket PEA Chlorophyll Fluorimeter. To account for variations in photosynthetic parameters across the surface of individual plants, the data presented are the average values obtained across individual rosettes at 3 points for more than $15 \mathrm{~min}$. All photosynthetic measurements were performed for four leaves of five individual plants.

\section{Gene expression analysis by semi quantitative RT-PCR and quantitative RT-PCR}

Total RNA was extracted using the TRIzol reagent (Invitrogen, Carlsbad, CA, USA). RNA was reversely transcribed using the Transcript One-step gDNA Removal and cDNA Synthesis SuperMix. The sequences of genes related to $S 40$ gene family were picked from rice genome database and their coding DNA sequences were used to design gene specific primers using Premier software as well as online NCBI tools. The specific primer pairs used for semi RT-PCR are listed in Additional file 1: Table S1 and qRT-PCR in Additional file 1: Table S2. Linearity for each amplification was confirmed and the products were visualized on agarose gels stained with ethidium bromide. qRT-PCR was performed in a total volume of $20 \mu \mathrm{l}$, including $1 \times$ Platinium_SYBR_Green qRT-PCR SuperMix-UDG, $0.3 \mu \mathrm{M}$ of each gene-specific primer and $10 \mu \mathrm{M}$ of fluorescein as the passive reference dye for well-factor calibration. To calculate qRT-PCR efficiencies, three different cDNA dilutions were applied. For comparison, transcript levels of mature leaves of the treatments were normalized to control. Each data point is based on nine independent 
measurements including three biological replicates and three technique replicates $(3 \times 3)$.

\section{Construction of the plasmids}

The expression vectors were constructed as follows: the coding sequences of the OsS40 genes were cloned into the entry vector pDONR201 (Invitrogen) by using the BP-clonase, according to the manufacturer's instructions, and subsequently cloned into the destination vector p2GWF7 (C-terminal GFP fusion-VIB, Ghent University, Belgium) by an LR reaction (Gateway recombination, Invitrogen). All of the fusion constructs were driven by the $35 \mathrm{~S}$ promoter. The specific primer pairs used are listed in Additional file 1 Table S3.

\section{Protoplast isolation, transformation and confocal microscopy}

The preparation of rice protoplasts was conducted based on a previously described protocol [85] with slight modifications. For isolating protoplasts, the stems and sheaths of 10-12 day-old young rice seedlings were cut into 0.5 $\mathrm{mm}$ strips with fresh razor blades and incubated in an enzyme solution containing 1.5\% cellulase 'Onozuka' RS (Yakulta), 0.4\% macerozyme R-10 (Yakulta) and 0.2\% pectinase (Sigma). After vacuum-infiltration and enzymatic digestion, the released protoplasts were collected by filtration through $40 \mu \mathrm{m}$ nylon meshes. Viable protoplasts were harvested by sucrose gradient centrifugation, washed once in W5 solution and then harvested by centrifugation and resuspended at a density of $2.5 \times 10^{6}$ cells/ml in MMG solution (0.4 M mannitol, $15 \mathrm{mM}$ $\mathrm{MgCl} 2$ and $4 \mathrm{mM}$ MES at $\mathrm{pH} 5.7)$ prior to PEG-mediated transfection.

For transformation, $10 \mu \mathrm{g}$ of plasmid DNA was mixed with $100 \mu \mathrm{l}$ protoplasts (about $2.5 \times 10^{6} \mathrm{cells} / \mathrm{ml}$ ) and $110 \mu \mathrm{l}$ PEG solution was added. Then, the mixture was incubated at room temperature for 5-10 min. After incubation, the mixture was diluted with $440 \mu \mathrm{L}$ W5 solution. The solution was fully mixed by gently inverting the tubes and the protoplasts were pelleted by centrifugation at $400 \mathrm{~g}$ for $2 \mathrm{~min}$. Transfected protoplast samples were resuspended in $200 \mu \mathrm{lW} 1$ solution and incubated at room temperature for $10 \mathrm{~h}$ in darkness allowing plasmid gene expression.

All microscopic observations were performed using a Leica TCS SP8 confocal laser scanning microscope. The fluorescence of the GFP was visualized with excitation and emission wavelengths of 488 and $505-535 \mathrm{~nm}$, respectively. Chloroplast auto fluorescence was visualized in a detection channel with excitation and emission wavelengths of 633 and $650-710 \mathrm{~nm}$, respectively. Image processing was performed with ImageJ (http://rsb.info. nih.gov/ij/).

\section{Detection of GFP-fused proteins by immunoblotting}

For each sample, $200 \mu \mathrm{l}$ transformed protoplasts were collected $12 \mathrm{~h}$ after transfection and denatured in $20 \mu \mathrm{l}$ protein loading buffer. SDS-PAGE and Western blot analysis were carried out using standard protocols [86]. The expression of GFP-tagged OsS40 proteins was assessed by immunoblotting using monoclonal anti-GFP antibody produced in mouse (Transgene) at a $1 / 3000$ dilution in 5\% BSA in TBS-T.

\section{Additional files}

Additional file 1: Table S1. Primers used for semi qRT-PCR for expression analysis of Os\$40 genes. Table S2. Primers used for qRT-PCR for expression analysis of Os\$40 genes. Table S3. Primers used for systemic subcellular localization assays. (ZIP $244 \mathrm{~kb}$ )

Additional file 2: Table S1. Cis elements in the promoters of $\$ 40$ genes in rice, HvS40 and AtS40-3. Promoter regions of 840 bp upstream of HVS40 and 1000 bp upstream of Ats40-3, and rice 540 genes were analyzed with the use of the PLACE program. W-box: Binding site for WRKY TFs; ERE: Elicitor response element; MYB: Myeloblastosis; LREs: Light regulated elements; MYC: Myelocytomatosis; ABRE: Abscisic acid responsive elements; Dof: DNA-binding with one finger; PRE: Pathogen response elements; SURE: Sulfur response elements; DRE/CRT: Dehydration response elements/C-repeat; LTR: Low temperature response; ARF: Auxin response factor; DPBFCOREDCDC3: BZIP TFs binding core sequence; G-box plus G: TF OsIRO2-binding core sequence. Table S2. Characteristics of rice $\mathbf{S 4 0}$ proteins. Characteristics of rice $\mathbf{S 4 0}$ proteins including theoretical isoionic point (PI), molecular weight (MW), Number of amino acids, instability index, aliphatic index and GRAVY (Grand Average of Hydropathy) predicted by ProtParam tool (http://web.expasy.org/protparam/). Figure $\mathbf{S 1}$. Exon-intron structures of $\mathbf{5 4 0}$ genes in rice genome. Yellow color shows CDS (exon), Blue color shows UTR (untranslated regions) while normal line represents introns. Figure S2. Distribution of Os\$40 genes on rice chromosomes. Chromosome Map Tool was used to located genes on chromosome. Figure S3. Amino acid sequences of the four Arabidopsis, two rice and one barley protein of group I compared to the sequence of the barley HvS40 protein. The conserved DUF584 domain sequence was highlighted in black and $100 \%$ identical residues in grey. Figure S4. Conserved motifs in HvS40, AtS40-3 and OsS40 proteins. a Motif structures for the proteins were determined using MEME search tool. Grey lines represent the non-conserved sequence. Each motif is indicated by a coloered box numbered at the bottom. b Moti logo obtained by MEME program. The overall height of each stack represents the degree of conservation at each position, while the height of letters within each stack indicates the relative frequency of amino acids. The motifs, numbered 110, were displayed in different colored boxes. Figure S5. Semi qRT-PCR expression analysis of the sixteen Os\$40 genes at different growth stages of flag leaves, labeled as 90DAG, 97DAG, 104DAG, 111DAG) and 118DAG. DAG (Days After Germination). Figure S6. Semi qRT-PCR expression analysis of the sixteen Os\$40 genes at different nitrogen concentrations. Genes marked with * indicate the differentially expressed genes that were further analyzed by quantitative real-time PCR. Figure S7. Semi qRT-PCR expression analysis of the sixteen Os\$40 genes during dark induced leaf senescence. Detached leaves from 4-week-old rice seedlings were incubated in the deionized water in darkness for 2 days (D). As a control, the detached leaves were incubated with water at the same time in a light/ dark regime $(\mathrm{L})$. Genes marked with * indicate the four differentially expressed genes that were further analyzed by Real-Time PCR. Figure S8. Detached leaves of four weeks old rice plants were treated with different concentrations (50uM, 100uM, 200uM) of ABA, SA, MeJa and IAA. Treatment with water was used as a control. The effect of the treatment was shown by the yellowing of leaves, which initiated after $48 \mathrm{~h}$ of treatment with $200 \mu \mathrm{M}$ concentration of these hormones. Figure S9. Semi qRT-PCR expression analysis of the sixteen Os $\mathrm{S} 40$ genes in respond to ABA, SA, MeJA or IAA treatment. Treatment with water was used as a control. 
Among them, eight genes showed altered expression at different time of treatment. Genes marked with * indicate the eight differentially expressed genes that were further analyzed by quantitative real-time PCR. Figure S10. Semi qRT-PCR expression analysis of the sixteen Os $\$ 40$ genes in responds to M. oryzae infection. As a control the rice seedlings were sprayed with the $0.02 \%(\mathrm{~W} / \mathrm{V})$ Tween 20 solution only (Mock). After inoculation, the leaves were collected at $24 \mathrm{hpi}, 48 \mathrm{hpi}, 72 \mathrm{hpi}, 96 \mathrm{hpi}$ and 108hpi for RNA extraction. Genes marked with * indicate the ten differentially expressed genes that were further analyzed by quantitative real-time PCR. hpi, hours post-inoculation. Figure S11. Immunoblot analysis of Cterminal GFP-tagged Os $\$ 40$ memebers transiently expressed in rice protoplasts. The corresponding GFP-tagged Os $\$ 40$ proteins with expected molecular sizes are pointed out with an arrow. The actin protein and Ponceau S staining were used to check the loading level. (ZIP $14091 \mathrm{~kb}$ )

\section{Abbreviations}

ABA: Abscisic acid; Chr: Chromosome; GFP: Green fluorescent protein; IAA: Idole acetic acid; MeJa: Methyl jasmonate; N: Nitrogen; qRTPCR: Quantitative real-time polymerase chain reaction; SA: Salicylic acid; SAGs: Senescence associated genes; SAM: Shoot apical meristem; SDSPAGE: Sodium dodecyl sulfate polyacrylamide gel electrophoresis; TFs: Transcription factors

\section{Acknowledgments}

We would like to thank Dr. Huakun Zheng (Fujian Agriculture and Forestry University) for his technical support in $M$. oryzae infection assay. We appreciate the reviewers and editors for the careful reading and patience to the work.

\section{Ethics approval and consent of participate}

Not applicable.

\section{Funding}

This project was financially supported by Natural Science Foundation of Fujian Province (2018 J01694 to X.Z.; 2015 N0019 to Y.M.), China National Science Foundation (NSFC 31701862 to X.Z.) and a scientific cooperation research foundation of National Key Laboratory of Plant Molecular Genetics of CAS (Shanghai) to Y.M., and a scientific research foundation of young scientist project of FAFU (xjq201717 to X.Z). The funders had no role in the design of the study, data collection and analysis, decision to publish, or preparation of the manuscript.

\section{Availability of data and materials}

All data generated or analyzed during this study are included in this published article and its supplementary information files.

\section{Authors' contributions}

$\mathrm{XZ}, \mathrm{MJ}$ and Habiba equally performed all the experiments, analyzed the data and revised the manuscript together as teamwork. $Y Z$ and $L L$ contributed in performing experiments including samples collection and RNA extractions. YM designed and supervised the whole project from the start of the experiments till writing of the manuscript. All authors read and approved the final manuscript.

\section{Consent for publication}

Not applicable.

\section{Competing interests}

The authors declare that they have no competing interests.

\section{Publisher's Note}

Springer Nature remains neutral with regard to jurisdictional claims in published maps and institutional affiliations.
Received: 30 October 2018 Accepted: 9 April 2019

Published online: 02 May 2019

\section{References}

1. Buchanan-Wollaston $V$, Ainsworth C. Leaf senescence in Brassica napus: cloning of senescence related genes by subtractive hybridisation. Plant Mol Biol. 1997:33(5):821-34

2. Lim PO, Kim HJ, Gil Nam H. Leaf senescence. Annu Rev Plant Biol. 2007:58:115-36.

3. Besseau S, Li J, Palva ET. WRKY54 and WRKY70 co-operate as negative regulators of leaf senescence in Arabidopsis thaliana. J Exp Bot 2012;63(7):2667-79.

4. Miao $Y$, Laun $T$, Zimmermann $P$, Zentgraf $U$. Targets of the WRKY53 transcription factor and its role during leaf senescence in Arabidopsis. Plant Mol Biol. 2004;55(6):853-67.

5. Jing S, Zhou X, Song Y, Yu D. Heterologous expression of OsWRKY23 gene enhances pathogen defense and dark-induced leaf senescence in Arabidopsis. Plant Growth Regul. 2009;58(2):181-90.

6. Han M, Kim C-Y, Lee J, Lee S-K, Jeon J-S. OsWRKY42 represses OsMT1d and induces reactive oxygen species and leaf senescence in rice. Molecules and cells. 2014;37(7):532.

7. Ricachenevsky FK, Sperotto RA, Menguer PK, Fett JP. Identification of Feexcess-induced genes in rice shoots reveals a WRKY transcription factor responsive to Fe, drought and senescence. Mol Biol Rep. 2010;37(8):3735-45.

8. Robatzek S, Somssich IE. A new member of the Arabidopsis WRKY transcription factor family, AtWRKY6, is associated with both senescenceand defence-related processes. Plant J. 2001;28(2):123-33.

9. Thomas H, Ougham H. The stay-green trait. J Exp Bot. 2014;65(14):3889-900.

10. Chen Y, Qiu K, Kuai B, Ding Y. Identification of an NAP-like transcription factor BeNAC1 regulating leaf senescence in bamboo (Bambusa emeiensis Viridiflavus'). Physiol Plant. 2011;142(4):361-71.

11. X-r T, R-k Z, Chen X, Wu X-j, Ming F. Characterization of OsNAP from Oryza sativa $\mathrm{L}$. and its application in molecular breeding. J Fudan University (Natural Science). 2012:51:507-14.

12. Zhang Y, Cao Y, Shao Q, Wang L, Wang H, Li J, Li H. Regulating effect of ZmNAP gene on anti-senescence and yield traits of maize. J Henan Agric Sci. 2012;41:19-24.

13. Weaver LM, Gan S, Quirino B, Amasino RM. A comparison of the expression patterns of several senescence-associated genes in response to stress and hormone treatment. Plant Mol Biol. 1998;37(3):455-69.

14. Distelfeld A, Avni R, Fischer AM. Senescence, nutrient remobilization, and yield in wheat and barley. J Exp Bot. 2014;65(14):3783-98.

15. Gregersen PL, Holm PB. Transcriptome analysis of senescence in the flag leaf of wheat (Triticum aestivum L.). Plant Biotechnol J. 2007:5(1):192-206.

16. Gregersen P, Holm P, Krupinska K. Leaf senescence and nutrient remobilisation in barley and wheat. Plant Biol. 2008;10(s1):37-49.

17. Parrott DL, Mclnnerney K, Feller U, Fischer AM. Steam-girdling of barley (Hordeum vulgare) leaves leads to carbohydrate accumulation and accelerated leaf senescence, facilitating transcriptomic analysis of senescence-associated genes. New Phytol. 2007;176(1):56-69.

18. Becker W, Apel K. Differences in gene expression between natural and artificially induced leaf senescence. Planta. 1993;189(1):74-9.

19. Krupinska K, Haussühl K, Schäfer A, van der Kooij TA, Leckband G, Lörz H, Falk J. A novel nucleus-targeted protein is expressed in barley leaves during senescence and pathogen infection. Plant Physiol. 2002;130(3):1172-80.

20. Humbeck K, Quast S, Krupinska K. Functional and molecular changes in the photosynthetic apparatus during senescence of flag leaves from fieldgrown barley plants. Plant Cell Environ. 1996;19(3):337-44.

21. Kleber-Janke T, Krupinska K. Isolation of cDNA clones for genes showing enhanced expression in barley leaves during dark-induced senescence as well as during senescence under field conditions. Planta. 1997:203(3):332-40.

22. Fischer-Kilbienski I, Miao Y, Roitsch T, Zschiesche W, Humbeck K, Krupinska K. Nuclear targeted AtS40 modulates senescence associated gene expression in Arabidopsis thaliana during natural development and in darkness. Plant Mol Biol. 2010;73(4-5):379-90.

23. Oh SA, Lee SY, Chung IK, Lee C-H, Nam HG. A senescence-associated gene of Arabidopsis thaliana is distinctively regulated during natural and artificially induced leaf senescence. Plant Mol Biol. 1996;30(4):739-54. 
24. Jehanzeb $M$, Zheng $X$, Miao $Y$. The role of the $\$ 40$ gene family in leaf senescence. Int J Mol Sci. 2017;18(10):2152.

25. Krupinska K, Dähnhardt D, Fischer-Kilbienski I, Kucharewicz W, Scharrenberg C, Trösch M, Buck F. Identification of WHIRLY1 as a factor binding to the promoter of the stress-and senescence-associated gene HvS40. J Plant Growth Regul. 2014;33(1):91-105.

26. Eulgem T, Rushton PJ, Robatzek S, Somssich IE. The WRKY superfamily of plant transcription factors. Trends Plant Sci. 2000;5(5):199-206.

27. Abe H, Urao T, Ito T, Seki M, Shinozaki K, Yamaguchi-Shinozaki K. Arabidopsis AtMYC2 (bHLH) and AtMYB2 (MYB) function as transcriptional activators in abscisic acid signaling. Plant Cell. 2003;15(1):63-78.

28. Yanagisawa S, Schmidt RJ. Diversity and similarity among recognition sequences of Dof transcription factors. Plant J. 1999;17(2):209-14.

29. Yang T, Poovaiah B. A calmodulin-binding/CGCG box DNA-binding protein family involved in multiple signaling pathways in plants. J Biol Chem. 2002; 277(47):45049-58.

30. Busk PK, Pages M. Regulation of abscisic acid-induced transcription. Plant Mol Biol. 1998;37(3):425-35.

31. Suzuki M, Ketterling MG, McCarty DR. Quantitative statistical analysis of cisregulatory sequences in ABANP1- and CBF/DREB1-regulated genes of Arabidopsis. Plant Physiol. 2005;139(1):437-47.

32. Jiang $C$, lu B, Singh J. Requirement of a CCGAC cis-acting element for cold induction of the BN115 gene from winter Brassica napus. Plant Mol Biol. 1996;30(3):679-84

33. Krupinska K, Dahnhardt D, Fischerkilbienski I, Kucharewicz W, Scharrenberg C, Trosch M, Buck F. Identification of WHIRLY1 as a factor binding to the promoter of the stress- and senescence-associated gene HvS40. J Plant Growth Regul. 2014;33(1):91-105.

34. Ay N, Janack B, Fischer A, Reuter G, Humbeck K. Alterations of histone modifications at the senescence-associated gene HvS40 in barley during senescence. Plant Mol Biol. 2015;89(1-2):127-41.

35. Desveaux D, Després C, Joyeux A, Subramaniam R, Brisson N. PBF-2 is a novel single-stranded DNA binding factor implicated in PR-10a gene activation in potato. Plant Cell. 2000;12(8):1477-89.

36. Desveaux D, Subramaniam R, Despres C, Mess JN, Levesque C, Fobert PR, Dangl JL, Brisson N. A "Whirly" transcription factor is required for salicylic aciddependent disease resistance in Arabidopsis. Dev Cell. 2004;6(2):229-40.

37. Waese J, Fan J, Pasha A, Yu H, Fucile G, Shi R, Cumming M, Kelley LA, Sternberg MJ, Krishnakumar $V$, et al. ePlant: visualizing and exploring multiple levels of data for hypothesis generation in plant biology. Plant Cell. 2017;29(8):1806-21.

38. Yoshida S. Fundamentals of rice crop science. Intrice Resinstlos Ba Os. 1981.

39. Liu L, Xu W, Hu X, Liu H, Lin Y. W-box and G-box elements play important roles in early senescence of rice flag leaf. Sci Rep. 2016;6:20881.

40. Lee RH, Wang CH, Huang LT, Chen SCG. Leaf senescence in rice plants: cloning and characterization of senescence up-regulated genes. J Exp Bot. 2001;52(358):1117-21.

41. Egli D, Leggett J, Duncan W. Influence of $\mathrm{N}$ stress on leaf senescence and $\mathrm{N}$ redistribution in soybeans. Agron J. 1978;70(1):43-7.

42. Schildhauer J, Wiedemuth K, Humbeck K. Supply of nitrogen can reverse senescence processes and affect expression of genes coding for plastidic glutamine synthetase and lysine-ketoglutarate reductase/saccharopine dehydrogenase. Plant Biol. 2008;10(s1):76-84.

43. Gregersen PL, Culetic A, Boschian L, Krupinska K. Plant senescence and crop productivity. Plant Mol Biol. 2013;82(6):603-22.

44. Masclaux-Daubresse C, Reisdorf-Cren M, Orsel M. Leaf nitrogen remobilisation for plant development and grain filling. Plant Biol (Stuttg). 2008;10(Suppl 1):23-36.

45. Guo Y, Gan S. Leaf senescence: signals, execution, and regulation. Curr Top Dev Biol. 2005;71:83-112

46. Khan M, Rozhon W, Poppenberger B. The role of hormones in the aging of plants - a mini-review. Gerontology. 2014;60(1):49-55.

47. Jibran $R, A$ Hunter D, P Dijkwel P. Hormonal regulation of leaf senescence through integration of developmental and stress signals. Plant Mol Biol. 2013;82(6):547-61.

48. Liang C, Wang Y, Zhu Y, Tang J, Hu B, Liu L, Ou S, Wu H, Sun X, Chu J. OsNAP connects abscisic acid and leaf senescence by fine-tuning abscisic acid biosynthesis and directly targeting senescence-associated genes in rice. Proc Natl Acad Sci. 2014;111(27):10013-8.

49. Hörtensteiner S. Stay-green regulates chlorophyll and chlorophyll-binding protein degradation during senescence. Trends Plant Sci. 2009;14(3):155-62.
50. Kusaba M, Ito H, Morita R, lida S, Sato Y, Fujimoto M, Kawasaki S, Tanaka R, Hirochika H, Nishimura M. Rice NON-YELLOW COLORING1 is involved in light-harvesting complex II and grana degradation during leaf senescence. Plant Cell. 2007;19(4):1362-75.

51. Morita R, Sato Y, Masuda Y, Nishimura M, Kusaba M. Defect in non-yellow coloring 3 , an $\alpha / \beta$ hydrolase-fold family protein, causes a stay-green phenotype during leaf senescence in rice. Plant J. 2009;59(6):940-52.

52. Kim Jl, Murphy AS, Baek D, Lee SW, Yun DJ, Bressan RA, Narasimhan ML. YUCCA6 over-expression demonstrates auxin function in delaying leaf senescence in Arabidopsis thaliana. J Exp Bot. 2011;62(11):3981-92.

53. Ellis CM, Nagpal P, Young JC, Hagen G, Guilfoyle TJ, Reed JW. AUXIN RESPONSE FACTOR1 and AUXIN RESPONSE FACTOR2 regulate senescence and floral organ abscission in Arabidopsis thaliana. Development. 2005;132(20):4563-74.

54. Lim PO, Lee IC, Kim J, Kim HJ, Ryu JS, Woo HR, Nam HG. Auxin response factor 2 (ARF2) plays a major role in regulating auxin-mediated leaf longevity. J Exp Bot. 2010;61(5):1419-30.

55. Hou K, Wu W, Gan SS. SAUR36, a small auxin up RNA gene, is involved in the promotion of leaf senescence in Arabidopsis. Plant Physiol. 2013;161(2):1002-9.

56. Xu F, Meng T, Li P, Yu Y, Cui Y, Wang Y, Gong Q, Wang NN. A soybean dual-specificity kinase, GmSARK, and its Arabidopsis homolog, AtSARK, regulate leaf senescence through synergistic actions of auxin and ethylene. Plant Physiol. 2011;157(4):2131-53.

57. Robert-Seilaniantz A, Grant M, Jones JD. Hormone crosstalk in plant disease and defense: more than just jasmonate-salicylate antagonism. Annu Rev Phytopathol. 2011;49:317-43.

58. Kazan K, Lyons R. Intervention of Phytohormone pathways by pathogen effectors. Plant Cell. 2014;26(6):2285-309.

59. Kaneda T, Taga Y, Takai R, Iwano M, Matsui H, Takayama S, Isogai A, Che FS. The transcription factor OsNAC4 is a key positive regulator of plant hypersensitive cell death. EMBO J. 2009;28(7):926-36.

60. Shimono M, Sugano S, Nakayama A, Jiang C-J, Ono K, Toki S, Takatsuji H. Rice WRKY45 plays a crucial role in benzothiadiazole-inducible blast resistance. Plant Cell. 2007;19(6):2064-76.

61. Swinburne IA, Silver PA. Intron delays and transcriptional timing during development. Dev Cell. 2008;14(3):324-30.

62. Jeffares DC, Penkett CJ, Bahler J. Rapidly regulated genes are intron poor. Trends Genet. 2008;24(8):375-8.

63. Chorev M, Carmel L. The function of introns. Front Genet. 2012;3:55.

64. Liang Y, Xiong Z, Zheng J, Xu D, Zhu Z, Xiang J, Gan J, Raboanatahiry N, Yin Y, Li M. Genome-wide identification, structural analysis and new insights into late embryogenesis abundant (LEA) gene family formation pattern in Brassica napus. Sci Rep. 2016;6:24265.

65. Xie DW, Wang XN, Fu LS, Sun J, Zheng W, Li ZF. Identification of the trehalose-6-phosphate synthase gene family in winter wheat and expression analysis under conditions of freezing stress. J Genet. 2015;94(1):55-65.

66. Patil A, Nakamura H. Disordered domains and high surface charge confer hubs with the ability to interact with multiple proteins in interaction networks. FEBS Lett. 2006;580(8):2041-5.

67. Ambawat S, Sharma P, Yadav NR, Yadav RC. MYB transcription factor genes as regulators for plant responses: an overview. Physiol Mol Biol Plants. 2013;19(3):307-21.

68. Boter M, Ruiz-Rivero O, Abdeen A, Prat S. Conserved MYC transcription factors play a key role in jasmonate signaling both in tomato and Arabidopsis. Genes Dev. 2004;18(13):1577-91.

69. Le Hir R, Bellini C. The plant-specific dof transcription factors family: new players involved in vascular system development and functioning in Arabidopsis. Front Plant Sci. 2013;4:164.

70. Phukan UJ, Jeena GS, Shukla RK. WRKY transcription factors: molecular regulation and stress responses in plants. Front Plant Sci. 2016;7:760

71. Miao Y, Jiang J, Ren Y, Zhao Z. The single-stranded DNA-binding protein WHIRLY1 represses WRKY53 expression and delays leaf senescence in a developmental stage-dependent manner in Arabidopsis. Plant Physiol. 2013;163(2):746-56

72. Wang X, Cai J, Jiang D, Liu F, Dai T, Cao W. Pre-anthesis high-temperature acclimation alleviates damage to the flag leaf caused by post-anthesis heat stress in wheat. J Plant Physiol. 2011;168(6):585-93.

73. Hafsi M, Mechmeche W, Bouamama L, Djekoune A, Zaharieva M, Monneveux P. Flag leaf senescence, as evaluated by numerical image analysis, and its relationship with yield under drought in durum wheat. J Agron Crop Sci. 2000;185(4):275-80. 
74. Liu L, Zhou Y, Zhou G, Ye R, Zhao L, Li X, Lin Y. Identification of early senescence-associated genes in rice flag leaves. Plant Mol Biol. 2008;67(1-2):37-55.

75. Noh YS, Amasino RM. Identification of a promoter region responsible for the senescence-specific expression of SAG12. Plant Mol Biol. 1999:41(2):181-94.

76. Jiang Y, Liang G, Yang S, Yu D. Arabidopsis WRKY57 functions as a node of convergence for jasmonic acid- and auxin-mediated signaling in jasmonic acid-induced leaf senescence. Plant Cell. 2014;26(1):230-45.

77. Otegui MS, Noh YS, Martinez DE, Vila Petroff MG, Staehelin LA, Amasino RM, Guiamet JJ. Senescence-associated vacuoles with intense proteolytic activity develop in leaves of Arabidopsis and soybean. Plant J. 2005;41(6):831-44.

78. Li Z, Peng J, Wen X, Guo H. Gene network analysis and functional studies of senescence-associated genes reveal novel regulators of Arabidopsis leaf senescence. J Integr Plant Biol. 2012:54(8):526-39.

79. Cai CZ, Han LY, Ji ZL, Chen X, Chen YZ. SVM-Prot: web-based support vector machine software for functional classification of a protein from its primary sequence. Nucleic Acids Res. 2003;31(13):3692-7.

80. Li YH, Xu JY, Tao L, Li XF, Li S, Zeng X, Chen SY, Zhang P, Qin C, Zhang C, et al. SVM-Prot 2016: a web-server for machine learning prediction of protein functional families from sequence irrespective of similarity. PLoS One. 2016;11(8):e0155290.

81. Zhou Y, Huang W, Liu L, Chen T, Zhou F, Lin Y. Identification and functional characterization of a rice NAC gene involved in the regulation of leaf senescence. BMC Plant Biol. 2013;13(1):132.

82. El Mannai Y, Akabane K, Hiratsu K, Satoh-Nagasawa N, Wabiko H. The NAC transcription factor gene OsY37 (ONAC011) promotes leaf senescence and accelerates heading time in Rice. Int J Mol Sci. 2017;18(10):2165.

83. Mao C, Ding W, Wu Y, Yu J, He X, Shou H, Wu P. Overexpression of a NACdomain protein promotes shoot branching in rice. New Phytol. 2007;176(2):288-98.

84. Mao C, Lu S, Lv B, Zhang B, Shen J, He J, Luo L, Xi D, Chen X, Ming F. A rice NAC transcription factor promotes leaf senescence via ABA biosynthesis. Plant Physiol. 2017;174(3):1747-63.

85. Zhang Y, Su J, Duan S, Ao Y, Dai J, Liu J, Wang P, Li Y, Liu B, Feng D. A highly efficient rice green tissue protoplast system for transient gene expression and studying light/chloroplast-related processes. Plant Methods. 2011;7(1):30.

86. Sambrook J, Maccallum P, Russel D: Molecular cloning: A laboratory manual, Cold Springs Harbour Press, NY. In.: ISBN 0-87969-577-3; 2001.

Ready to submit your research? Choose BMC and benefit from:

- fast, convenient online submission

- thorough peer review by experienced researchers in your field

- rapid publication on acceptance

- support for research data, including large and complex data types

- gold Open Access which fosters wider collaboration and increased citations

- maximum visibility for your research: over $100 \mathrm{M}$ website views per year

At $\mathrm{BMC}$, research is always in progress.

Learn more biomedcentral.com/submissions 